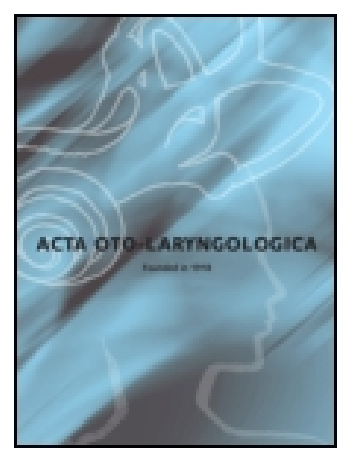

Acta Oto-Laryngologica

\title{
On Cerebral Abscesses of the Frontal Lobe issuing from the Frontal Sinus and Other Intracranial Complications resulting from Inflammatory Processes of the Nasal Accessory Sinuses
}

\section{Frithjof Leegaard}

To cite this article: Frithjof Leegaard (1918) On Cerebral Abscesses of the Frontal Lobe issuing from the Frontal Sinus and Other Intracranial Complications resulting from Inflammatory Processes of the Nasal Accessory Sinuses, Acta Oto-Laryngologica, 1:1, 343-407, DOI: 10.3109/00016481809122006

To link to this article: http://dx.doi.org/10.3109/00016481809122006

曲 Published online: 08 Jul 2009.

Submit your article to this journal ¿

Џ Article views: 1

View related articles $\longleftarrow$ 
HROM THE DEPARTMENT FOR FAR, NOSE AND TIROAT DISEASES, MIKShosptTAIET (UNIVERSTTY hOSPITAL), ChRISTIANIA, NORWAY.

(CHIEF SLRGEON: PROF, Y. LCHERMANA.)

\title{
On Cerebral Abscesses of the Frontal Lobe issuing from the Frontal Sinus
}

\author{
and \\ Other Intracranial Complications resulting from Inflammatory \\ Processes of the Nasal Accessory Sinuses.
}

By FRITHJUF LEERAARID.

Former 1:st Assistant Surgeon.

A treatise published in 1916 by Büller on the aftertreatment of otitic brain abscesses begins with the following words:

"Die Errfahrungen auch der beschäftigsten Chirurgen ïber den Hirnabscess sind bei der verhältnismässig grossen Seltenheit dieser Erkrankung begreiflicherweise nicht allzu ausgedehnt. Es dürfte daher von Vorteil sein, diesen Mangel an weiterreichenden Erfahrungen des Finzelnen durch Zusammenstellung der Ansichten verschiedenen Autoren und durch neue Beiträge einigermassen wett $\mathrm{zu}$ machen. Gerade hier können statistische und kasuistische Mitteilungen die Kenntnisse wesentlich erweitern und im praktischen Falle nutzbar gemacht werden."

This statement applies to cerebral abscesses issuing from the ear. And yet our knowledge of these abscesses has been considerably extended in the course of the last generation through the studies of a number of eminent authors. In a much greater degree, therefore, will the same statement apply to the rhinogenic cerebral abscesses. For these 
latter, as well as all other intracranial complications in general issuing from the nose or its accessory sinuses, occur far more rarely than the otogenic abscesses. Our knowledge regarding then and still more our experience in their treatment are therefore still very incomplete. For that reason it may be permitted to assume that the history of some cases belonging to this category will be of interest.

In the Ear. Nose and Throat Department of the Rikshospital I have had occasion to observe during the last couple of years 3 cases of cerebral abscess arising out of frontal sinusitis. Besides these there has occured one other case of the same kind since the establishment of the department 25 years ago, thus making 4 cases altogether.

In the following pages I shall set forth the history of these 4 cases and shall add i few remarks regarding these abscesses, especially as to their diagnosis and treatment.

Moreover, I shall give an account of the other intracranial complications issuing from the accessory sinuses of the Nose that have occurred in the Ear, Nose and Throat Department, and finally I shall relate the history of a case belonging to this class, which has been kindly placed at iny disposal from another source.

I.

\section{Abscesses in the Frontal Lobe.}

\section{First rase.}

Ruguhild E., 19 years old. Admitted on the 29th of April 1899 ; died on the 4th of May 1899. Hitherto always in good health. During the last 6 weeks severe nasal catar $h$ with plentiful discharge of mucus, said to be no pus, no offensive smell. Fight days ago severe headache with shivering. languid and unfit for work. Has lain in bed for the last 3 days. During the last couple of days she has noticed pus in discharge from nose. Headache has been violent, localised to forehead. Has frequently 
vomited. Yesterday there was noticed some swelling over the eyes and in the eye-lids.

\section{Condition on :29th April 1899:}

Pale. Complains of pains in the head. Somewhat stuporeons. Pulse: 10x. Temperature: 40.1. Tongne: dry, with white conting. Slight tenderness on pressure on upper part of the bridge of the nose and over the right eye-brow. No changes in the skin. () n rhinoscopy pus is seen between the conca media and septum is well as outside and under the concha media on both sides. The mucous membrane on the conchal is congested and somwehat hypertrophic, especially on the fore part of the concha media. Urine: trace of albumen. With cold snare and conchotom the anterior part of the concha media was remored on both sides; there came a quantity of pus.

April 30th. Temperature: 40.1--40.0. Harilly slept at all last night. Somewhat drowsy. Complains of pains in the forehead. llizziness. No romiting. Movement of pupils normal, no squuinring (strabismus). On rhinoscopy there is scen on the right side vellowish-white pus, which after removal appears again inmediatwy. On the left side there are seen only some yellowish-white rags. On trial lavage of the antrum of Highmore no pus was found.

Operation. with use of chloroform as anxsthetic.

Vertical incision from the middle of the forebead to the upper end of the bridge of the nose. At a right angle to this incision " horizontal incision from the boundary line between tho medial and the middle third of the right eye-brow to the corresponding point on the left side. In the anterior wall of both frontal sinuses an opening was made as large as the tip of the finger. Both sinuse's were filled with granulations and a thick, yellowish-white pus, with no offensive smell. (iranulations are spread all over the walls and extend down into the canalis naso-frontalis: they arr removed with a sharp spoon and doublecurette. On the posterior surface the hone is seen to be deprived of its periosteum on a space about as large as a 25 -ire piece. The channel down to the nose is made wider. The wound is sewn up again, no tampon, no clrainage.

May 1st. Temperature: $39.3-38.8$. Complains of headache, Has not slept. Drowsy. Pulse: 120.

May 2nd. Lay in a somnolent state yesterday, responded, however, when spoken to, but only sluggishly. Got rather restless in the course of the evening. Slept one and a half hour last night. Lying to-day also in a half sleep with closed eyes, answers sluggishly, Complains of healache and pain in the lumbar region. 
Pulse: 84. Pupils equal in size, somewhat dilated. Ophthalmoscopic examination: dilated veins.

Two attacks of vomiting, one last night and one this morning. No cramps, no stiffnes in the back of the neck. The left arm seems to be paretic, as she in spite of repeated requests cannot return hand-pressure, whereas she does so with the right hand. Temp. at 4 o'clock p. m. 38.4. Pulse: 72, a little soft. The right upper eye-lid still somewhat swollen, more so than the left one.

5.30 p. II. Operation under chloroform.

Anterior wall of frontal sinuses is completely removed. Tow:ards the upper and outer part on both sides are found some remnants of granulations.

On the right side the posterior wall of the frontal sinus is removed for a space about the size of a 1 -orre piece about $1 \mathrm{~cm}$. from the middlr line. The dura is of a dirty yellowish colour. On the left side a similar portion is removed; the dura here is of normal appearance.

On the right side a horizontal incision is then made through the dura, whereupon some drops of purulent, dirty-grey fluid inmediately come out. On introduction of a "searcher" pus amounting to about 1 teaspoonful is met with at a depth of about $1 \mathrm{~cm}$. The cavity extends backwards for about $3 \mathrm{~cm}$. The walls are somewhat softened; no firm membrane. Careful scraping out of the cavity with a sharp spoon. Insertion of a drainage-tube. Iodoform gauze-plug. Bandage. Pulse after operation: 84, regular.

May 3rd. Temp. 38.2-37.5. Very restless the whole night, wanted to get out of bed. Answered when spoken to. Passed urine in bed. Convulsive twitchings in left arm, occurring twice. No vomiting. Soporous to-day. Pulse: 112. Mouth drawn over to right side. Now and then twitchings of the lower lip, which thoreby is drawn over to the right. Left arm seems to be paretic lying bent in the elbow: on attempting to straighten it some regidity is observerl.

May 4th. In the course of yesterday forenoon it state of coma leveloped. Was at times very restless. Pulse sometimes very frequent (about 1:0), sometimes slower (about 70). No vomiting or cramps. Otherwise unchanged. Yesterday evening at 10 o'clock dressings changed. Drainage-tube removed. No retention of pus. There came a good deal of venous hemorrhage from the dura. also some bleeding from the drainage-tube opening in the brain. On account of the rather profuse hemorrhage no new drainagetube inserted. Iodoform gauze-plug. Bandage. Lay afterwards in deep coma. Died last night at 4.30 a. m. Post-mortem refused. 


\section{Epicrisis.}

In addition to the frontal lobe abscess it is very probable that meningitis has also been present in this case. even though the symptoms mentioned in the diary do not prove this with certainty. The paresis in the left arm is in interesting point. That goes to show that the absces: or the encephalitic changes have extended a long way backwards. It may however, also be explained by assuming meningitic changes around the sulcus centialis.

\section{Second Case.}

Alfied, $F ., 15$ vears old. Admitted March 8th 1916. Died March 30th 1916.

Hitherto in good health. On the 2nd of March the patient: left eye began to flow profusely, while at the same time the eye became somewhat red. $\mathrm{He}$ is also said to have been feverish: had several attacks of vomiting as well as headache. Next day, swelling around the left eye, especially of the upper eye-lid. There has been no secretion of pus from the nose, neither was thire any stuffiness in the nose. Since yesterday (March 7 th) the swelling is said to have gone down a little; the healache has also been less severe during the last few davs than in the beginning.

Condition on March 8th 1916.

Looking rather ill and haggard. No pains at the present moment. Pulse 84, regular, good. Temp. 38. (armpit). Considerable swelling on left upper eye-lid. Skin ower same red and heated. Lower eve-lid also swollen, but to a lesser degree. Palpebral fissure almost closed. Conjunctiva bulbi et palpebrarum considerably swollen and red. Bulbus protruding very much. The. whole swelling feels oedematous, pasty, whitout distinct fluctuation. Considerable tenderness of the left upper orbital edge. Also a little oedema of the coverings over the glabella and of the right eye-lid. On anterior rhinoscopy there is seen pus in the left middle passage of the nose. The mucous membrane on the concha inferior but especially on the concha media on the left side is very much swollen. On posterior rhinoscopy ther is likewise observed a great deal of swelling and redness of the concha media and pus in the middle passage. On transillumination no definable shadow over the antrum Highmori. Otherwise normal conditions.

March 8th, evening. Operation with morphia-chloroform-ather marcosis. (Kuhns intubation). 
Incision as with Killian's operation. Coverings very much swollen, grevish, gelatinous. By the incision a subperiostal abscess was evacuated, which contained a couple of teaspoonfuls of dirtygrey pus of very offensive odour. The bone over the orbita was exposed for a considerable space. There was found a slender fistula in the front part of the lamina papyracea, leading upwards towards the sinus frontalis. This was small (about $1 \mathrm{~cm}$. in extent) and filled with fetid pus. The anterior and middle ethmoidal cells were filled with greyish granulations and were removed. A part of the concha media was likewise removed. In making the passage down to the nose a considerable part of the proc. frontal. maxillae sup. and of the os nasale were removed. In the bone above the supra-orbital edge the diploetic chambers contained small vellow pus-foci, while the bone was somewhat discoloured. So much of this latter was removed that the hard, sound bone was everywhere reached. A position suture in the upward direction. Tamponade of the wound as well as a separate tampon down through the nose.

March 10th. Since operation feeling well, no pains. Highest temperature 37.9 (yesterday evening). To-day, 36.8. Dressings changed. Hardly any swelling around the wound. Much less protrusion of bulbus. Movements of the eve seem to be in the main normal.

March 14th. There has been some increase in the evening temperature, which was 38.1 yesterday. To-day, 38.9. The swelling in the soft parts has almost entirely subsided. Hardly any protrusion of the bulb. The conjunctiva slightly congested. Morement of the eye appears to be normal, except when looking upwards, in which direction it is somewhat restricted. On changing dressings considerable secretion of pus from the medial angle of wounil.

March 15th. Morning temperature: 38.1. Evening temp. 38.3. At 3 o'clock this aftarnoon whithout any previous symptoms the patient got an epileptiform attack with general convulsions of about 1 minute's duration, followed by insensibility. which lasted about 10 minutes. A similar attack at $\mathbf{5}$ o'clock in the afternoon. On reinoval of tampon after last attack considerable secretion of pus. Removal of suture. Inspection of wound. Between the periosteum and the bone at the back in an upward direction a little pus was found. Otherwise nothing to remark. A strip of gauze introduced between the periosteum and the bone at the spot mentioned. Since patient came in the pulse has been between 76 and 88 .

March 16th. No attack since yesterday. Slept well. Feels well. Considerably less secretion on changing dressings: 
March 19th. Temperature has gradually gone dowin, to-day 3 T. Pulse has been between 78 and 88 .

March S3rd. Temperature on the whole has been normal: highest temperature 37.2. The pulse has become slower. This morning 56 , this evening 60 . In the course of the last 3 days he has been dronsy and during these days has had diffused and fairly severe headuche. Answers sensibly, but languidly, mostly only "Yes" and "No". No romiting or nausea. Has hardly eaten anything during the last few davs. The pupils large, reacting sluggishly.

This evening at $i$ o clock: Inspection "f wound.

Chloroform was administered, but after getting $4 \mathrm{gr}$. he was pale and unconscious, wherefore no more chloroform was given. A part of the posterior wall of the frontal sinus was removed with chisel. The bone was found to be thickened and i little decayed. The dura seemed normal. In the outer prart of the frontal sinus a section about $1 \times 1 \mathrm{~cm}$. in size was removed. The remaining part of the orbital roof was founcl to be denuded of periosteum and covered with granulations. There also appeared a few 4holss of pus here. A cavity about the size of an alınond was reached witl, the probe. Here the dura was laid bare in the upward direction and the cavity was full of granulations. The mentioned part of the orbital roof was removed with the forceps. The wound was cleansed with a louble-curette and plugged with sterilised gawze. A strip of gauze was introduced downwards through the nose. After the operation the patient stated that he felt relieved. He spoke sensibly. Pulse: 76.

March 24th. evening. Slept fairly well last night. Since this morning he has become a little more drowsy. Vomited this afternoon at 6 o'clock. The pulse has again gone donm to 56 . Temperature: $36 .$. . Therefore there was nade this evening at 7 oclock, without urncosis, a fresh inspection of wound with examination of the frontal lobe through the dura corresponding to the frontal sinus. The dura was here found to be somewhat thickened, no pulsation. An incision about $1 \mathrm{~cm}$. long was made through the dura and was enlarged to $2 \mathrm{~cm}$. with a blunt instrument. In the meninges there was nothing noticeable. On inserting a Pean's pincers for alout $1 \mathrm{~cm}$. there exucled a quantity of ycllowish-green fitill pus. which filled the whole of the frontal wound-altogether ahout 2 tablespoonfuls of pus. The abscess cavity was egg-shaped and extended backwards for about $5 \mathrm{~cm}$. After evacnation the cavity was cleansed with gauze and a sharp spoon. A drainagetube, split lengthwise, was inserted, going about $2 \mathrm{~cm}$. inside the ppening and fixed with a safety-pin. Sterilised gauze bandage. Waveh 25th. Tsess headache since operation. Patient livelier 
more talkative. No vomiting. Pulse: 64. Dressings changed and opening in dura enlarged. Culture from the abscess: staphylococcus pyogenes aureus (pure culture).

March 26th. Condition same as yesterday. On changing dressings considerable secretion of pus noted. Pulse in the afternoon: is.

March 27th. Drowsy. Complains of headache. Pulse: 58. Vomited after taking orange-juice. Some pus found on changing dressings. Salt-vater plug inserted instead of drainage-tube.

March 28th. Pulse: 52. Temperature rising, yesterday evening, 38.2; to-day 38. Vomiting yesterday evening and last night. J'erfectly clear in mind. Complains of headache. Twitchings in the left arm two or three times this morning. Dressings changed. After removal of tampon and lilatation of abscessopening about 1 teaspoonful of pus was evacuated. A slight prolapsus in an upward and outward direction, which blocked the passage, was removed. The walls of the abscess-ravity are found to have grown together, so that there is no room for a drainage-tube. When the tube is inserted into the opening it is immediately pressed out again. A strip of sterilised gauze is introduced into the wount. Yesterday evening and to-day the patient complained of pains in the left lumbar region and under the costal arch. Tendemess in the region of the kidneys. Kidney not palpable. Urine dark, cloudy. Specific gravity: 1,026, contains a little albumen. re-acts strongly to bloodtest, no pus or sugar. Microscopic test: numerous red blood-corpuscles, renal epithelium. conglomerate and separate blood-corpuscle fibrines.

March 29th. Pulse 56. Temperature: yesterday crening, 38.3, to-day, 38.4. Yesterday evening repeated attacks of vomiting. Since change of dressings yesterday a quantity of pus mixed with blood oozed out from under the bandage. Has slept a little. Headache seems better to-day. His mind is clear. Take; a little sour milk. There is considerable stiffness in the back of the neck and incipient opistotomus. On changing dressings to-day a prolapsus the size of a walnut is seen to have come through the opening in the dura. In the afternoon a puncture in the lumbar region was made, whereby 12 cubic centimetres of rather turbid liquid was evacuated. Beginning pressure, $400 \mathrm{~mm}$., final pressure, 250 unm. Pandy positive. 10,800 uhite blood corpuscles, chiefly polynuclear lencocytes.

After the lumbar puncture less stiffness and prain in back of neck. On removal of the dressings there came away a lump of cerebral matter about as large as the prolapsus previously mentioned, with dark discolorations in several places. Afterwards the patient lay still and quiet. Died at 3 oclock a. m. Post-mortem refused. 
Epicrisis.

From a sinusitis frontalis (plus ethmoiditis) accompanied by important exterior symptoms, especially in connection with the ev'. there developed in the course of quite a short time an alscess of the frontal lobe, which assumed considerable dimensions. In spite of this abscess being opened. the case had a fatal issue owing to the development of meningitic complications. The rapid progress of the illness and dirty-grey, extremely fetid pus seem to mint to malignant infection. The occurrence of cramps is rspecially note-worthy. In the first place there were the two epileptiform attacks. and then there were the twitschings in the arm on the same side as the abscess. Convulsions in cases of cerebral abscess are, of course, nutling unusual, especially in the case of children and voung persons. On the other hand convulsions in connection with abscess of the frontal lobe occurring on the sime side as the abscess have been mentioned onle by Donalies in a single case and he has not been able to give any explanation of the phenomenon. In the present case it may probably be due to the meningitis, which at the time the twitchings in the arm occurred - the day hefore death - must have been fairly extensive.

\section{Third Case.}

Peter G.. 19 vears old. Admitted Feb. 20th 1917. Died August 5th 1917 .

Hitherto in good health. In the middle of December 1916 he lay in bed for three days with headache and vomiting. About 3 weks ago he caught a heary cold with nasal catarrh and headache, lay in bed for $\mathbf{j}$ days. The catarrh has persisted since then, on both sides all the time. Last week he has again lain in bed on account of severe pain in the region of the forehead. Also on this occasion he has repeatedly vomited. On the 16th of February he noticed offensive odour from the nose.

Condition on February 20th 191\%.

The patient is pale and looks rather run down. Pulse: 52, 
regular. Temperature: 37.7 (armpit). Strong offensive odour from nose. The right palpebral fissure somewhat smaller than the left, the right "pper eye-lid slightly oedematous. Some tenderness on pressure over the eye-brows, increasing upwards to the middle of the forehead. Extreme tenderness on pressing against the floor of the frontal sinus on both sides. No oedema in the foreheat. The septum nasi shows considerable deviation towards te left, so that the upper part of the left nasal cavity cannot be survered. The murous membrane of the nasal cavity is hyper:mic, bleeiling a little. The right nasal cavity is roomy, the anterior extremity of the concha media is hypertrophic, pale and coated with pus. On examination of the organs nothing abnormal to he found. Cirine: albumen negative.

Feb. 22nd. On transillumination a shadow was seen over the left antrum of Highmore. On puncture pus was found. A wirle opening of the left antrum Highmori was made from the lower nasal passage. During the following davs lavage of the left antr. Highm. Under this treatment the swelling around the right eye decreases. Patient gets up, but feels weak and still complains of headache. Bowels constipated. Pulse keeps at abont 60 , a couple times at 52, on one single occasion (March $3 \mathrm{rl}$ ) down to 48. Temperature about 38. On one evening 37.5.

Mareh oth. Still complains of headache and is remarkably tirerl. To-day there is again noticed puffiness around the right eye and swelling of the eye-lid.

Under cloroform-narcosis. Radical operation of the simus frontulis dext.

At the first stroke of the chisel on the usual spot pus exudes. The bone is unusually thin. The mucous membrane in the sinus oedematous and swollen. The cavity, which is about the size of an almond, contains some of granulations. On the posterior "rall pus is seen oozing out from a very small opening. After reanoval of the anterior wall of the cavity and part of the lower one and after enlargement of the canal down to the nose, where granulations are found, the posterior wall of the frontal sinus is remover. A little pus immediately comes out. The dura is found to be thickened, a little yellowish in colour, covered with granulations at certain spots. An incision about $1 \frac{1}{2} \mathrm{~cm}$. in length is made through the dura and then a puncture with a closed artery-pincette, whereupon there comes out only a little pus. Then a blunt Pean's forceps is inserted for about $2 \mathrm{~cm}$., whereupon there bursts out a large quantity of fetid pus, about 2 tablespoonfuls. A strip of vioform-gauze is inserted in the opening to the abscess. No suture. After operation pulse 76 , half an hour later, 60. Diplococci were cultivated from the pus. 
March 6th. Pulse: 52. Temperature: 36.4. The opening to the abscess has closerl up, the strip of gauze has been driven out. On re-opening with Péan's forceps a large quantity of fetid pus strearns out. After evacuating the contents as completely as possible a slightly bent tracheal canula was inserted, being introduced by means of a conductor. The rest of the wound cavity was then plugged.

March 7 th. Slept last night without acetocyl, which he hal not done previously. On changing dressings it seems that the canula has drained well. The abscess cavity is proceeding to close up. Un examination with Péan no retention.

March 9th. Temperature yesterday and to-day below 37. Pulse to-day more rapid, about 100 (this morning 64). Yesterday sever. pain in the forehead, had to be given morphia. The canula has been driven out. Abscess cavity closed. To-day there is nore swelling in the forehead and the right upper eye-lid, fluctuation. By incision a subperiostal abscess was opened and about 1 teaspoonful of pus evacuated. The sinus frontalis is filled up by a prolapsus.

Subsequently there developed an attack of erysipelus which spread over the whole of the face and neck and down to the middle of the back. Was treated with fomentations. From March 20th the temperature was normal (below 3i). From April 5th till May 7 th a little fever (up to 38.3), afterwards again below 37. In connection with the erysipelas an abscess formed in the right upper eye-lid and a subperiostal abscess in the forehead on the right side. Both of these were lanced. From the beginning of May all secretion had practically ceased. The prolapsus, which had grown to the wall of the frontal sinus was gradually loosened and an attempt was made to reduce it by careful compression by the bandage. It shrunk to about the size of a finger-tip. On the 24th of May the patient began to sit up. On June 8th the evening temperature was 38 , and he complained of slight headache.

June 9th. An attack of vomiting. The prolapsus a little larger. Evening temperature: 38.2.

June 10th. Vomiting. Some headache.

June 11th. On examination with a blunt curved forceps inside of the prolapsus more than a teaspoonful of somewhat fetid pus streams out, after which the headache gets better, The abscess seems to be situated in the prolapsus itself. Dry dressings as before. Evening temperature 37.9.

From June 12th temperature again normal (below 37.). Secretion from the above-mentioned opening has almost entirely ceased, the prolapsus has again become smaller and the headache abated. On June 27 th the patient got up again. He felt quite woll 
temperature normal and pulse between 70 and 90 . The pulse, it may be remarked, had not been below 64 since March 6th, the day after the opening of the cerebral abscess.

Iuly 19th. Patient had again a slight headache and the evening temperature was 38.7. Pulse: 108. On the 3 following days the evening temperature was between 37.6 and 37.7 .

July 22nd. Vomited in the afternoon.

July 31st. Temperature has remained normal since July 23rd. He has had a little headache and on certain days (July 26th, 27 th, 28th, 30th, 31st) an attack of vomiting. On inserting a blunt forceps in the opening inwards from the prolapsus, which, by the way, is now almost covered by a growth of skin, about half a teaspoonful of mucous pus was evacuated. After this the patient feels relieved.

August 2nd. Had again a single attack of romiting, but feels better otherwise. Appetite increasing.

August 4th. Felt quite well the whole day. Ate supper with appetite. Evening temperature: 38.4 (after having for 10 days perfectly normal temperature and pulse between 60 and 70). He went to sleep as usual without the attendants noticing anything remarkable. At 1 o'clock he began to moan and immediately lapsed into unconsciousness. The arm and log on the left side became paralysed (the face, however, appeared to be unaffected). Pulse: 160. Became by degrees completely comatose and died at + o'clock. Post-mortem refused.

\section{Epicrisis.}

The symptoms of sinusitis frontalis on the rigth side which were present on the patient's admission temporarily disappeared after the empyema in the antrum on the left side had been opened. Still, the patient suffered all the time from headache and felt by no means well. His pulse was also remarkably low. When the patient 13 days after admission was operated for the sinusitis frontalis, the supposition that there existed a cerebral abscess was confirmed by the findings in the frontal sinus. In the posterior wall there was a small opening, from which pus exuded. There existed therefore, at any rate, an epidural accumulation of pus. The dura being laid bare also showed alterations that pointed to a more deep-seated lesion. And after an incision had been made in the dura large quantities of fetid pus were evacuated by means of Péan's 
forceps. The rase seened at first to be inclined to run a favourable courst. In spite of several abscesses in the soft tissues and under the periosteum and in spite ef $\mathrm{ex}$ tensive erysipelas the patient improved and two and a balf months aftor the operation he began to sit up. But 14 days later he again had headache. slight fever and vomiting. There was found and opened an abscess; apparently situated in the prolapsus that had developed, which prolapsus, however. had decreased in size. He improved again and was once more able to get up. But about 1 month later le got the same symptoms again and a fresh accumulation of pus was evacuated. Some few days after this - 5 months after the original operation - he suddenly hecame unconscious and died in the course of a couple of hours, showing signs that pointed to a penetration into the ventricle system. The symptoms which preceded the two last evacuations of pus must therefore be assumed nut to have been caused by a superficial retention alone. There has probably existed a more deep-seated accumulation, extending pretty far backwards. The hemiplegia of the left side which supervened just before death points in this direction. The patient died of a secondary abscess. This is the danger that always lurks in the background. rven when a cerebral abscess has been located and opened and even if therr are no other intracranial complications present.

\section{Fourth Case.}

Rolf, K.. ${ }^{2} 2$ years old. Admitted July 14th 1917. Discharred Sept. 7th 1917. Re-admitted Sept. 18th 1917. Discharged IIarch 3rd 1918.

Suffered from enlarged glands in childhood. Otherwise always in grood health. Since the spring of this year has been troubled with nasal catarrh with thick, yellow mucous discharge on both sides, but not accompanied by headache. Got worse during the summer, owing it is said to his having lain in a tent near a river (military service). On the 5th of July he got headache, nostly. localised to left side of the forehead. At the same time he had prain around the left eye, which on July 6th swelled up very much.

1 Demonstrated in the medical society Christiania Narch fith 1918. Acta oto-laryngologira, 
The eye-lids became red and swollen, so the oye could not be. opened. Was admitted to a small country infirmary, where he has since been treated with compresses until to-day, when a small incision was made in the left upper eye-lid, but without any pus roming out. This afternoon he was admitted as an urgent rase to the Rikshospital's Eye Department, from which he was at once transferred to the Ear and Throat Department.

Condition on July 14th 1917.

Pale and thin. Complains of headache in the forehead and pain around the left eye. Pulse: 92. Temperature: 37.5 (armpit). On the left side there is considerable swelling in the region of the foreheud and the eye-lids are likewise much swollen, red and glued together. so that he can just barely open the eye. In the medial portion of the upper eye-lid there is a hard patch of limited extent, not fluctuating, in which there is seen a small opening ifter the aborementioned incision. Some tenderness along the margo supraorbitalis, mostly in the medial portion. Considerable chemosis conjunctivx. Cornea clear and specular. Bulbus greatly protruding and displaced in the downward and outward direction, immovable.

Anterior rhinoscopy: The mucous membrane of the nose is swollen and congested. On the right side the concha media partially coated with half-dried, thick yellow mucus. On the left side pus is seen both in the middle nasal passage and in the olfactory region. Un posterior rhinoscopy the same conditions were observed. The septum is found to be deviated to the left, so that in the upward direction it almost touches the lateral wall.

Heart and lungs: condition normal.

July 1oth. Radical operation of the sinus frontalis sin. under morphiaælher narcosis (Kuhn's intubation).

Coverings much swollen, oedematous. Sinus frontalis contained a considerable quantity of vellow pus. Mucous membrane greatly swollen. The cavity extended outwards only to the middle of the eye-brow, but extended pretty far upwards and especially far over towards the right side, where its boundary coincided more or less with the centre of the right eye-brow. Between the sious frontalis and the orbita there was a large ethmoidal cell filled with pus. The whole of the ethmoidal labyrinth was full of swollen, polypoid mucous membrane, which was removed-A wide communicating passage was made down to the nose, in making which a considerable part of the lateral nasal wall had to be removed on account of septal deviation. No penetration of the bone was anywhere noticed. Strip of sterilised gauze from the cavity down through the nose. Primary suture. On July 16 th the evening temperature was 39.8. Afterwards normal temperature, rising occasionally in the evenings 
to between 35.3 and 38.3 . During the whole time he was in the hospital the pulse remained as a rule between 72 and 80 , nevor slower than 72. During the first month after the operation he complainerl a good deal of hearlache and made on the attendant: the impression of being rather peevish and cross. On August 12th ha had a single attack of vomiting after eating. The swelling around the aye gradually climinished. There continued, however, for a long time a puffiness in the uppor eye-lid beneath the op cration-wound, where an abscess was lanced on August 14th and ahout half a teaspoonful of thick, yellow pus was evacuated.

On the th $^{\text {th }}$ of September everything had healed up. There wits still some discharge from the nose. He felt well. Had inrreased $16.7 \mathrm{~kg}$. in wright from Julv 25 th to Sept. 4th. Discharged.

On Sept 1:3th - 5 days later - he became suddenly very ill. had severe headache localised to the left side of the forehead and to the back of the neck: had to go to bed and has since been lying. On attempting to get up ho becomes very giddy, so that he is on the point of falling. On Sept. 16th he had an attack of vomiting. likewise on the morning of the 18th. On Sept. 18th he was again admitted to the same department of the hospital in a condition of great suffering and moaning with pain. The left "Ye and its surroundings were in the same state as when he wits discharged on Sept. 9th. No (onspicuous tenderness. No distinet stiffness of the neck, but the patient winces when the head is bent forwards. Kernig positive (which disappeared after injection of morphia). Pulse: 64. Temperature: 37.3.

Immediately after admission an operation under morphia-nor\%ruin ancesthesia was performerl.

Incision through the old scas. Also a rertical incision ahout 2 ('m in length upwards from the medial end of the first incision corresponding to the eanth. int. Opening of the sinus frontalis, which contained only a quantity of fibrous tissue. No change in the bone in the wall of the eavity. The dura was laid bare for a space about the size of a 10-orre piece by removal of a portion of the posterior wall of the frontal sinus. The suriace of the dura showed no distinct changes. It was taut, pulsating, and seemid to bulge forward a little. On puncture with a thick needle pus was net with at a depth of about one and a half centimetres. Thereupon an incision about $1 \mathrm{~cm}$. in length was made in the dura, which was here felt to be rather considerably thickened. A closed forceps was inserted into the opening made by the incision, which was caused to gape apart by opening the forceps. Thereupon about 35 cubic centimetres (carefully judged) of thick yellow odourless pus were evacuated very slowly and carefully. A split drainage-tube was inserted about $1 \mathrm{~cm}$. from the surface and was 
sutured to the lower corner of the wound. Dry dressings. Patient stated that headache was relieved after operation. Pulse: $72-76$. From the pus there developed diplococci.

Sept. 19th. Has been feeling well. No vomiting. At bloody liquid has soaked through the dressings. The drainage-tube lies cutside the opening in the dura. On separating the edges of this opening by means of a forceps there werc evacuated 2 or 3 teaspoonfuls of matter, consisting partly of a quite thin fluid, slightly mixed with blood, and partly of small purulent lumps. A strip, of sterilised gauze was carefully inserted in the opening of the dura. The walls of the cavity of the abscess seem to have conte together, as the forceps meets with a soft substance immediately inside the opening.

During the following 3 or 4 days a similar amount of matte! was evacuated in the same manner. Afterwards the secretion from the opening in the dura was very slight. The dressings were shanged daily and the edges of the opening were separated every time hy means of a forceps. The opening in the dura "losed up 1 month after the operation. During the after-treatment, the part of the wound corresponding to the exposed portion of the dura gradually bulged out more and more in the form of a hemispherical tumour, covered with granulations. This protrusion attained its greatest dimensions 6 weeks after the operation. It was then about as large as a walnut and rose a little above the level of the frontal bone. Afterwards it gradually subsided and had disappeared about 2 months after the operation. The wound continued for a long time to secrete a little, but by the middle of December it had become covered with skin. The pulse was never slow after the operation, generally about 80 . The temperature during the first 16 days after the operation showed occasional slight increases in the evenings, up to 38 . Afterwards it became normal (below 37). On December 11 th he got up. On the 2 following days he had an evening temperature of 37.4 and $3 i .3$, so therefore went to bed again. Slight increases in the evening temperature continued until December 19th, afterwards without fever. Got up again on January 1st 1918. Subsequently completely without fever, with the exception of two short periods of feverishness, which could not be attributed to his original malady (from 23rd to 26th January pain in joints acompanied by fever and on February 11 th and 12 th angina accompanied by fever).

The patient's general conditions and appetite were generally speaking excellent after the operation. When weighed for the last time on February 5th his weight was $80 \mathrm{~kg}$. that is to say, he had put on $6.2 \mathrm{~kg}$. more since the date of his discharge after the first stay in the hospital. 
On February 12th he was discharged. The operation scar was then firm and solid. In the upper part of the nasal cavity on the left side there was an inconsiderable quantity of half-dried secretion. There was still some alteration in the eve: the bulbus protruding a little and displaced in a downward and outward direction with double images $i$ the left-hand and upper portion of the field of vision. (Paresis of the rectus superior, together with contraction of the rectus inf. - Rikshospital's Eye Clinic).

Re-examination on April 19th: Feels perfectly well. No secretion found in nose. Examination of eye (Rikshospital's Eye Clinic) shows normal strength of vision. Left papilla a little paler than the right one. Otherwise as stated above.

\section{Epicrisis.}

The treatment, as may be seen from the above history of the case, was very conservative. This conservative procedure was based upon a line of reasoning which was arived at under the impression drawn from the progress of the 2 previous cases and which was as follows:

When an inflammation proceeds from the frontal sinus to the brain through the meninges and the result of this is an abscess, that is to say, a limitation of the pathological process in the brain, this may be regarded as the beginning of an effort on the part of nature to cure itself. The consolidations in the tissues that have taken place and the formation of a more or less distinct memblane may be regarded as a protective barrier for the surrounding brain tissue. It is now the business of the surgeon to meet the efforts of nature half way and to secure an outle tfor the pus with a minimum of traumatism and infection of the healthy brain tissue. The drainage of a cerebral abscess is generally established either by means of a drainage-tube or by inserting a tampon in the abscess cavity with or without lavage. In each case there is a certain anount of risk of lesion or infection of the surrounding tissue with consequent encephalitis and meningitis. It is therefore doubtful whether it is expedient to employ the same thorough-going, but somewhat violent, method as is used in the treatment of abscesses in other parts of the body. It may be that it will be better for the patient to confine 
oneself to securing free passage for the pus every time the dressing: are changed and in the meantime only to leave a small tampon lying in the opening in order that the latter may not close up.

The fact that the course of the malady in this case was favourable is one more proof amongst many of the wonderful healing powers that nature possesses. On the other hand it is, of course, dangerous on the basis of a single case to draw far-reaching conclusions with regard to the treatment of such abscesses. I shall, howerer, later on revert to the questions touched on alove.

\section{Frequency.}

All absress of the frontal lobe complicating a sinusitis frontalis is a rather uncommon thing. Nevertheless, this complication arises considerably more frequently than one was inclined to suppose about twenty years ago, to judgo from existing literature. The statistics regarding intracranial complications in connection with affection of the accessory sinuses are as Onodi remarks. by no means to be regardod as complete. It cannot, however, be denied that they are of great interest.

In 1896 Dreyfuss could not classify more than 19 certain cases altogether of sinusitis frontalis accompanied by intracranial complications. In 1908 the same author was able to increase that figure to $\$ 8$, and of these 36 were abscesses of the frontal lobe. In 1909 Gerber found in the whole range of medical litterature 66 cases of such alsscesses mentioned. And finally in 1914 Boenninghans was able to state the number of published cases of abscess of the frontal lobe arising from this cause to be 87. As may be seen, the number of published cases has increased indeed but is as yet ly no means of imposing dimensions.

\section{Symptoms and Diagnosis.}

All authors emphasise the fact that the symptoms of frontal lobe abscess are not very distinctive and that therefore the diagnosis is generally very difficult. Gerber in 
his exhaustive work "Die Komplikationen der Stirnhöhlenentziundung" begins the chapter on the symptoms of these abscesses with the following pointed remark: "Das häufigste Symptom des Frontallappenabscesses ist seine Symptomlosigkeit."

The division into 4 separate stages: the initial stage: the latent stage, the manifest stage and the terminal stage, which is made in the case of otitic cerebral abscesses, is also employed in the symptomatology of frontal lobe abscesses. But as regards these latter it is still more difficult than in the case of otitic abscesses to separate the different stages. This is especially due to the fact that in the case of cerebral abscesses arising from an inflammation of the frontal sinus focal symptoms are hardly ever to be seen. In the case of brain abscesses issuing from the ear there are, on the contrary, in the manifest stage frequently symptoms, which allow to determine the location of the abscess and confirm the diagnosis of its existence. So important is this, that Körner when speaking of the diagnosis of otitic brain abscesses begins by mentioning the focal symptoms which are of significance for differential diagnosis between temporal lobe abscess and cerebellar abscess. As regards otitic abscesses the diagnostics have in recent years made a considerable advance, since Bárány has proved that in the cerebellum there exist centres which govern the movements of the joints in the different main directions and that paralysis or irritation in these centres may be clinically ascertained by means of the pointing tests.

The conditions as regards frontal lobe abscesses are different. In these cases as a rule no focal symptoms are to be found. Such symptoms do not appear until the abscess has become very large and begins to extend in a backward direction. Thus in certain cases facial paralysis, strabismus, as well as motoric and amnestic aphasia have been described.

Justly famous is Hammersfahr's case:

In combination with sinusitis frontalis on the left side there developed symptoms of brain pressure, paresis of the oral part of 
the facial nerve on the right side and partial amnestic aphasia. An abscess was diagnosed in the posterior part of the lower frontal convolution. On operation the abscess was found at the spot mentioned, 2 centimetres below the surface of the brain. It contained about 1 tablespoonful of pus. The pationt was cured.

An interesting case, which has some similarity to this. has been published from Holmgrens hospital.

A 25-year-old woman developed, in combination with actute sinusitis frontalis et maxillaris on the left side, symptoms of an intracranial complication. After evacuation of an epidural abscess the symptoms temporarily subsided, But 1 week afterwards there appeared paresis in the left arm, and after some days this developed into hemiplegia. There was diagnosed a deep-seated abscess in the right pariotalregion. On trepanning over the right parietal lobe: a large abscess was found at a depth of 3 centimetres. In spite of the opening of the abscess the patient's life could not be saved. A postmorten revealed a large abscess in the tract of the capsula interna. No connection with the epidural abscess could be discovered, for which reason the abscess was regarled as being metastatic.

In general in making the diagnosis one must be content vith the etiology of the case (the sinusitis; combined with the more or less distinct signs of intracranial pressure. In this way the diagnosis has in many cases been succesfully accomplished. But this nearly alwavs demands a certain time for observation. And often the mode of proceeding is to operate in the first place for the sinusitis. The symptoms do not disappear, as had been expected. They rontinue, nay more, they increase. Gradually it beromes clear that there exists something more than an inflammation in the frontal sinus and then finally the cerebral abscess is diagnosed. This case is so typical that on reading through the history of cases one finds these conditions recurring again and again almost with the regularity of a law.

In the next place I shall go through the most important symptoms and in judging their value I shall lay spe(ial stress upon what is to be learned from the cases described above and as far as possible shall endeavour to 
utilise the information I have gained from these 3 cases, which I have personally observed.

In the first place I shall mention the headache. This is, of course, a symptom that is very common in the most dissimilar forms of illness. This symptom might therefore be considered as being of little importance as a point of support in the diagnosis. Especially, it is risky to attich too much weight to headache because it is a symptom that also belongs to the original malady, the sinusitis, and. yet, from what I have seen, this symptom is of considerable value. Not, however, on account of its localisation: for that is not a characteristic feature. Frequently, no doubt, the pain is situated in the region of the foreheal. but it may also be localised to the back of the neck. Or it may be diffused.

But what frequently distinguishes this headache is it: serverity. Among patients with uncomplicated sinusitis fromtalis I have never noticed anything like such violent healaches as in the case of the 3 patients suffering from frontal lobe abscess, whom I have observed.

Practically speaking, the question whether an existing sinusitis has led to an intracranial complication now hardly ever arises before the pus in the frontal sinus has been removed by means of an operation. If a violent headache exists afterwards. it points in the direction of an intracranial complication.

The nature of that complication is, no doubt, often difficult to decide with certainty. We meet here similar diagnostic difficulties as in the case of otitic complications. It must, however. be remarked that the cerebral abscess is the intracranial complication that most frequently arises in connection with sinusitis frontalis. Besides, in the case of meningitis and of the rarely occurring thrombo-phlebitis (in the sinus longitudinalis et cavernosus) we have otber symptoms which are of more or less decisive importance for differential diagnosis. And, finally, as regards the epidural abscess, this abscess, especially when it has attained certain dimensions, may yield symptoms that are quite 
similar to those of the cerebral abscess. A confusion between these two may therefore very easily occur. It must, however, be remembered that the epidural abscess as an independent malady is of much more seldom occurrence. Besides, there is no doubt that a very severe headache and a serious general condition should rather lead us to suspect the existence of a cerebral abscess. However, the differential diagnosis between these 2 maladies is not of great practical importance. The situation will become clear inder the operation.

While, as stated above, considerable diagnostic significance may be attached to an intense headache. it must not on the other hand be forgotten that the headache may not be a very prominent symptom. We may count upon this being the case if the abscess is small or if it has secured an outlet through a fistula. Thus in the case of Rafin's patient, where the abscess had an outlet through a fistula in the upper eye-lid, the headache occurred only when the fistula was rlosed. When it was open there were no pain.

Another important, but unfortunately far from constant, svmptom in connection whiht cerebral abscess is the slow pulse. This symptom enjoys. if I may use the expression, an altogether too unqualified respect. Thus Macewen in his classical work mentions slow pulse as an important diagnostic without making any reservation. Oppenheim on the other hand draws attention to the fact that there exist individuals whose pulse habitually has a frequency of 60 or helow. Körner in his work on otitic cerebral complications mentions a case in which the pulse was 52, where the patient, a 17-year-old girl, had a -schläfriges Wesen ", but where all symptoms, including the slow pulse, disappeared after an ordinary mastoidal resection. Also Ucherman n mentions that with men of calm, sluggish temperament a normal pulse-rate of 56 may be found.

There is every possible reason for bearing in mind, as the above-named authors do that slow pulse is of no seldom occurrence among healthy individuals. 
In the next place it must not be forgotten that a slow pulse may have its origin in maladies that belong to quite a different category. I shall not attempt to enumerate the various possibilities, but shall merely mention as an example a case that has recently been met with in the Eirr and Throat Departement of the Rikshospital: Total resection was performed on a 9-year-old girl for an uncomplicated chronic otitis on the right side. Two weeks after the operation she began to complain a little of headache, she got attacks of romiting and her pulse went down in the course of a few days from 70 or 80 to 60 . She did not, however: give the impression of being very ill. And some days after the appearance of the above-mentioned $\therefore$ 'mptoms there developed an icterus, which accounted for the slow pulse and the other phenomena.

A further example to show how cututious one nust lie in judging the symptom a slow pulse is found in the history of the following case, which $I$ shall deal with at some length, as is also contains other points of interest.

Rolf H., 20 years old. Admitted Sept. 26th 1914. Dischargerl tictober 20th 1914. One month ago had left corner-tooth in upper jaw extracted for toothache. Afterwards caught cold. A few days before admission got headache on left side, feverish, swelling und redness of eye-lids. On admission had also swelling down over cheek. Looks ill, answers languidly, but is clear of mind. Some chemosis conjunctivae. Slight protrusion of the eye(?). No tenderness in the forehead, but slight tenderness one pressure against the orbital roof inwards. On ophthalmoscopic examination: sightly distended veins. On anterior rhinoscopv: pus in middle nasal passage. Pulse on admission was 96 (visiting puls?) and temperature 37.6 The following day, pulse 52. At the same time the patient was drowsy, clear-minded, answered correctly but very languidly when questioned. Complained of headache. Extremi tenderness below the left inferior orbital edge, where the soft tissues were felt to be slightly infiltrated. Slight tenderness of the floor of the left frontal sinus, no tenderness in its anterior wall. On puncture of the left sinus maxillaris a quantity of pus was evicuated. In morphia-ether narcosis (Kuhn's intubation, Denker's operation. In the sinus maxillaris the mucous membrine in the medial wall was swollen and of grevish colour and there was a 
small quantity of pus, likewise in the ethmoidal cells. After the operation all the phenomena subsided in the course of 5 or 6 days. But the pulse remained slow, varying between 52 and 50 , except that it was twice down to 48 and on one single occasion up to 72 (with a temperature of 36.8 ). He was discharged fully cured. Re-examination on May 21st 1918: Has had no trouble since leaving hospital. Seems quite clear in mind. Rhinoscopic examination gives no sign of inflammation of accessory sinus. Pulse: 56.

I will here also mention a case that Killian has reported Arch. f. Lar. Bd. 13).

A 23-year-old patient with double sinusitis frontalis had a pulserate of 52 , which went further down to 48 . A radical operation was undertaken, after which the pulse rose to 60 in the course of 1 week. Afterwards generally 72. Subsequently he was operated for sinusitis maxillaris. During plugging after this operation the pulse again sank to 48 . No intracranial complications were found and the patient was curen.

Killian regards it as "quite clear that with this patient the slow pulse arose owing to reflex action from the accessory sinuses:. We ought. therefore, also to bear in mind such retlex action.

Considering the fact that the frequency of the pulse amongst healthy people may vary within fairly wide limits, it is rxceeding important to be able to follow the movements of the pulse of patients with sinusitis frontalis during " fairly long period of time. While the occurrence on a single occasion of a comparatively slow pulse is not a very reliable symptom, we are on the other hand entitled to attach considerable weight to decreasing pulsefrequency, even if the slowness of the pulse, absolutely regurded, is not very conspicuous. This fact is illustrated by three of the cases reported above. I would specially draw attention to the 4th case, where there existed an abscess of the frontal lobe without any other intracranial complications. In this case the pulse on the patient's first admission to the hospital was 92 and it remained during the whole of his first stay in the hospital between 72 and 80 . But 
when the patient was admitted for the second time the pulsefrequency was 64 , that is to say. it was about 10 heats below his usual rate. This decrease in the pulsefrequency was thus not very striking; but it was manifest. For the question whether or not there existed a cerebral abscess considerable significance was therefore at tached to it, side by side with the other symptoms. riperially the violent headache.

I have allowed myself the dwell upon the above-named fact, namely, the significance of the relatively slow pulse, because the symptoms of cerebral abscess are often obscure and we must therefore take advantage of every means in order to arrive at a correct diagnosis. In order to ascertain a slight decrease in the frequency of the pulse it is, of course, necessary to have the patient under observation for some time and during that time constantly to note the pulse-rate a couple of times every day. With patients suffering from sinusitis frontalis and other affections of the accessory sinuses), where the symptoms are $\therefore$ serious that an important operation is demanded, one should therefore during the whole of the treatment note the pulse-rate, even if there is no suspicion of intracranial romplications: for such a pulse-record may be of value later on.

As already stated, the slow pulse is far from being a (onstant symptom. In cases of cerebral abscess the pulse may be either normal or rapid, and it may also be varying. as for instance in our lst case, where towards the end it rscillated between about 70 and about 120. At that point of time however, there no doubt also existed meningitis.

The condition of the pulse has also a certain significance for the prognosis. After the operation one can generally, as in the 4 cases reported above, note an in"rease in the pulse-frequency. The only one of our patients that was cured had during the whole time after the operation a pulse-rate of from 70 to 80 , and neither did he during that time show any other serious symptoms. In the case of the other 3 patients on the other hand the 
rise in the pulse-rate after the operation was only temporary, but under circumstances entirely different in the different cases, concerning this point I refer to the history of the rases.

It is, of course, impossible on the basis of these few rases to draw definite general conclusions. But the facts: observed are nevertheless worth noting. Moreover, it may be added that, even if the pulse remains slow for somc time after the operation, the patient may nevertheles: recover, as in Rische's case, where during the 5) davs immediately following the operation the pulse was down to 48, and in Herzfeld's case, where it remained slow $(48$ to 58 ) for 1 week after the operation.

Regarding the otitic cerebral abscesses $\mathrm{Körner}$ says that disturbances in the sensorium ne never absent during the manifest stage. The same assertion may probably also be made regarding the abscesses we are treating of here, at any rate if the dimensions of the abscess are not altogether too insignificant. Thus in the case of our 4 patients the sensorium was more or less altered. As regards the 2 firts patients there was distinct drowsiness present. The third patient was inert and gave an impression of peevishness inot noted in the diaryl. Finally, the fourth patient was peevish and "cross" during his first stay in the hospital. That this was a symptom of his malady was clearly shown after the abscess had been opened. He then proved to be of an aimable and cheerful disposition. In the cases reported by medical authors we likewise find ronstant reference to changes in the sensorium and in the psychic state, for example, weakening of the memory and irritability (Wiener) inclination to sleep (Denker), stupor, apathy (Freudenthal), apparent stupidity (Rische), the patient answers "langsam und hinfällig, aber richtig "(Donalies)," peculiar alteration in character": (Reinking).

The symptoms mentioned may be assumed to be general cerebral symptoms. The supposition that the psychic functions are connected with the left frontal lobe and that 
from the absence or presence of psychic symptoms we should be able to draw conclusions regarding the seat of the malady (Gerber) is unfortunately without solid foundation. Neither does it appear from medical litterature that it has been possible to the author's to make use of such a diagnosticum.

On the contrary it is precisely the unfortunate thing that with abscesses of the frontal lobe focal symptoms are generally lacking. I will here mention that among our 4 patients the first developed paresis in the contralateral arm and in the facial nerve (?), symptoms which are of importance when in the ase of a patient with double sinusitis one has to decide on which side the cerebral complication is situated. In the case of our third patient there appeared immediately before death a paralysis of the arm and leg on the opposite side of the abscess. Local paralysis is. however, of not soldon oceurrence with such patients.

Neither is the occurrence of convulsions anything unusual. Either general. as with our second patient, who had two epileptiform attacks. Or localised, as with our first patient: who had convulsive twitchings in the left arm. As a rule. as in the case of this patient, the localised convulsions appear on the opposite side to the abscess. Nevertheless, Donalies has observed oconvulsions on the same side, which at first led to an erroneous focal diagnosis, the sinusitis being on both sides. The abscess, however, was afterwards located and the patient cured. Convulsions have also been described by a number of other authors, for instance: Grinwald, Wiener; Paunt\%, Freudenthal, Rafin.

Vomiting is a symptom that was present in all our \pm cases and in some of them a very conspicuous symptom. In each of the cases this symptom appenred at a comparatively early stage. As regards the first 3 patients it was noted already before admission and with the fourth patient vomiting occurred on one occasion during his first stay in the hospital, when we had not yet symptoms that might lead us to suspect the existence 
of a cerebral alsscess. Vomiting is, to be sure, a very usual symptom in many maladies and a single attack of vomiting must not, of course, be at once interpreted as a sign of cerebral abscess. On the other hand we must. not underestimate the importance of this symptom for the diagnosis. We must have our eyes open to the possibility of the existence of such an abscess when with patients suffering from frontal sinusitis there occurs vomiting, for which no other satisfactory explanation can be found. Especially, of course, when the romiting occurs independently of meals.

Giddiness is less frequently mentioned in medical literature than vomiting. Thus in the case of our 4 patients it only occurred with the first and fourth. In the case of the latter the giddiness was so much in evidence that he could not stand on his legs.

Of other symptoms which are mentioned in case-history, but which are of less importance, I shall name: stiffness in back of neck. incontinence, changes in sensibility and reflexes, decided loss of flesh, attacks of shivering. All of these are rare and, moreover, the are not distinctive features.

The state of the temperature offers nothing characteristic, as is also clear from the history of our 4 cases. It may be normal or subnormal, there may be a trifling rise, or there may be fever. The significance of a rise in temperature in each separate case may be difficult to determine. It may be due to the sinusitis, to an ocular complication or to some other intracranial complication (vieningitis, sinusphlebitis). As a rule it is not possible to draw diagnostic conclusions. This much, however, may be asserted, namely that considerable rise of temperature does not necessarily form part of the clinical picture in cases of cerebral abscess.

Neurits optica and stasis of the papilla have been described in a number of cases. The presence of these symptoms points in a positive direction when there is a question of intracranial complications in connection with frontal sinus- 
itis. Apart from the first case there is, unfortunately, nothing noted on this point in the history of our cases.

On the other hand I may draw attention to other symptoms or complications proceeding from the eye. Swelling of the eye-lids was found in all our 4 patients. Sometimes it was very extensive, as with patient $n \mathrm{r}$, who got an abscess of the eye-lid which had to be lanced. Swelling of the eonjunctiva was recorded in the cases of patients nr 2 and $\mathrm{nr} 4$, the chemosis being in the last-named case very pronounced. With the same patients there was a considerable protrusion of the bulbus. In the case of $\mathrm{nr} 3$ the operation revealed an orbital abscess. Finally, as regards $\mathrm{nr} 2$ the history of the case prior to admission shows that a flow of tears from the eye was the first symptom the patient noticed. Similar discoveries are frequently recorded in the history of cases of frontal lobe abscess. For example: orbital-phlegmon (Cargille), abscess of the eye-lid (Pauntz, Rische, Rafin), oedema of the eye-lid (Freudenthal), exopthalmus (Heimann).

Now, of course, these external ocular symptoms in themselves prove nothing in the question whether or not there exists an affection of the contents of the cranium. Strictly speaking, they only signify that the inflammation in the frontal sinus threatens to extend, or has already extended to the orbita and the contents thereof. But the oculoorbital complications are known to appear comparatively often in those cases of sinusitis which are accompanied by intracranial complications. And thereby they acquire a certain diagnostic value. While the frequency of ocular complications (de Lapersonne cit. from Hoffmann) in connection with frontal sinusitis may be estimated at 20 $\%$ (no exhaustive casuistry exists), it has been proved that these complications arise far more frequently in connection with abscesses of the frontal lobe issuing from the frontal sinus. Thus in Gerber's collection they constitute $50 \%$ of 64 cases.

It will not be out place to call to mind here what Bönninghaus asserts, namely, that hardly a single case 
of intracranial complication issuing from the nasal accessory sinuses (excluding the sinus sphenoidalis) has bern described without mention being made of swelling in the facial or orbital wall of the accessory sinus, while the opposite is the case with complications arising from inflammations in the ear, especially those which are (hronic.

The presence of oculo-orbital and other external symptoms of inflammation must be interpreted as an expression of the tendency of sinusitis to extend to the surrounding parts, whatever may be the cause of this more malignant clevelopment (the nature of the infecting matter, the organism's slight resisting-power or the imperfect outlet for the secretion in the frontal sinus). It is quite natural that this malignant tendeney of sinusitis should also manifest itself in the extension of the inflammation through the cerebral wall of the frontal sinus and thus result in abscess of the frontal lobe and other intracranial complications. Especially in the presence of acute external symptoms we must therefore be on our guard for the possibility of cerebral complications.

The condition of the call of the frontal simus and of the dura mater can, of course, only be determined with certainty in the course of the operation itself; macroscopic changes in these parts may sometimes have a certain amount of significance for the diagnosis.

It seems to be a fact that the posterior wall of the frontal sinus is in most cases clearly affected. Among 49 cases in which Gerber found this point mentioned affection of the posterior wall was stated to exist in 44. Generally it was a question of necrosis (33 cases). Among our 4 cases nr 3 showed a narrow opening in the posterior wall. In the case of $\mathrm{nr} 1$ and nr 2 there were changes, but not to any. pronounced degree ("the bone was laid bare", and "the bone thickened, a little decayed "). And in the case of our 4th patient there were no changes at all to be observed. 
Changes in the dura are met with in most cases (Killian). The dura is found to be covered by granulations and tense (Denker), pale and tense (Pauntz), of bad appearance, dirty-grey (Gerber), "prall hervorgewölbt' (Freudenthal), covered with granulations (Rische), tense and protruding (Rafin), yellowishgray, discoloured (Donalies), decayed and discoloured (Herzfeld, ulcerated and perforated (Orlandini, cit. from Gerber). Frequently it is recorded that the dura is pulseless, a symptom to which, however, there seems in all quarters to be attached very little importance. With regard to what was observed in the case of our own patients, the dura in the first rase was "dirtv-grey, yellowish", with our second patient "thickened, not pulsating", with $\mathrm{nr} 3$ "thickened, somewhat yellowish, in some places covered with granulations." Finally, in the case of the last patient the surface showed no distinct changes, the dura was pulsating and seemed to be tense and bulging a little.

The importance of the condition in which we find the posterior wall of the frontal sinus and the dura may be described as follows: When we find morbid changes in these parts, this fact strengthens the assumption that a cerebral abscess exists. If no changes can be proved to exist, it is often best to make a halt at the dura and to watch the development of the situation for a day or two before going further in. But if the symptoms point strongly in the direction of an abscess, we must not allow ourselves to be deterred, but must take measures at once, even if the changes in the dura are of a very uncertain nature. Just as in our 4th case, where a postponement of the opening of the cerebral abscess would probably not have been without danger to the patient.

\section{Treatment.}

If we have now duly ascertained the presence of a carebral abscess, the battle is not yet won. The therapeutic difficulties are by no means small. This is proved 
by the lack of agreement that has prevailed and still prevails on the various questions concerning the treatment, and perhaps to a still greater degree the aftertreatment. The views which are maintained concern, generally speaking, both rhinogenic and otogenic cerebral abscesses. What can be asserted regarding the one class of abscesses, can on the whole be equally well asserted about the other class, even though the circumstances are not quite alike for the localisation in the different rases.

That a cerelural abscess must be opened is generally agreed. But as to how this should be done, how large the opening ought to be, how we shall deal with the abscess cavity during the operation and how the after-treatment is to be conducted, on all these important points there is a wide difference of opinion. And on all these questions we can yuote good names in support of absolutely opposing views.

The first question that arises is: where shall we look for the abscess that has been diagnosed? In this respect. we are more or less happily situated. Körner has, as is well known, in the cases of otogenic cerebral abscesses laid down the principle that abscess practically speaking always lies in the neighbourhood of the primary suppurative process in the temporal bone. This law can be extended to abscesses issuing from the frontal sinus. We can with fairly great certainty count upon the cerebral abscess not being far distant from the cerebral wall of the frontal sinus. It is therefore directly behind this latter that we must look for the abscess. And we may count upon hitting on the right spot, even if the changes in the dura do not clearly point out the way, which they, moreover, frequently do.

In what manner shall we now make the entry into the assumed abscess? It is here that the difficulties and dissensions begin.

Shall we make a proof puncture through the whole of the dura or shall we first only make a slit? And what 
instrument shall we use for puncturing? Many authorities warn us against puncture through the whole of the dura. Others prefer that method of procedure, especially Heine, who after he adopted the use of a thick needle has never found that method to fail; neither has he experienced any disadvantage in the employment of such a means of puncture. On the other hand the same author has had the experience that incision with a knife proved unreliable in one case, where pus had been found on previously making a puncture. Körner in his book on the otitic cerebral complications warns us against puncture through the whole of the dura. After such a puncture he noticed profuse intrameningeal hemorrhage from the vessels of the pia mater. He therefore says that the dura must first be slit. Nevertheless, Körner himself, in the case of frontal lobe abscess recorded by Rische from Rostocker Hospital, performed a puncture through the whole of the dura with a Pravaz syringe, immediately found pus, evacuated the abscess and cured the patient. (Z. f. O, Bd. 62, S. 232). Also Rafin made a puncture with a Pravaz syringe in his case (the first recorded cure of abscess of the frontal lobe). without, indeed, finding pus but also without harmful results. Paunz proceeded in the same manner and on the second insertion found pus in the syringe.

Those who condemn the method of making a puncture through the whole of the dura emphasise, in addition to the danger of hemmorrhage, the possibility that the puncturing needle may convoy infective matter from the meninges into the brain-tissue and thus occasion infection of the latter. Both Körner and Zaufal record that they have had this experience. Likewise Brieger (cit. from Guttmanni. Also Uchermann for the reasons mentioned above warns us against puncturing through the whole of the dura. He first makes with a sharp-pointed knife a little opening in the dura, lifts the latter up with a sharp hook to avoid lesion of vessels of the pia mater. Thereupon he extends the opening and finally makes at right angles to it a small incision in order to get a better 
view of the meninges and to be able without using force to introduce the puncturing instrument. For making the puncture he employs a slender Péan's forceps, which is inserted while closed to a suitable depth and then cautiously opened and drawn out.

One must with Heine admit that a previous slitting of the dura involves a more extensive interference and that also in this way the infective matter may be conveyd farther in. It has also been alleged against the slitting of the dura that one thereby runs the risk of a prolapsus. (Koch, eit. from Guttmann).

In addition to the needle, knife, Péan's forceps there has also been employed as exploring instrument a trochar and an instrument called "searcher", specially constructed for this purpose by Macewen, although it cannot be seen from the litterature that these latter offer any special advantages.

If from what has been set forth above we shall now try to adopt a definite standpoint in the question here dealt with, it must be admitted that it is not very easy to do so.

The ideal method would be one which enabled us to determine with certainty whether or not there existed an abscess and at the same time exposed the patient to no risk whatsoever. Such a method does not exist. One must therefore try to adopt the mode of procedure that comes as near as possible to the ideal requirements.

Personally $I$ am of the opinion that one must not feel oneself absolutely bound to any single method. As to what specially concerns abscesses of the frontal lobe I have arrived at the following conclusion. These abscesses, by the time we are in a position to diagnose them with any approach to certainty, have as rule attained pretty large dimensions. Thus all the 3 abscesses $I$ have observed were large. And on perusing the history of cases in the litterature it will be seen that also the abscesses operated in other quarters have practically always been of respectable dimensions. These large abscesses, I believe, 
rannot easily escape discovery on puncture through the whole of the dura, if one uses a fairly thick needle 11 to $2 \mathrm{~mm}$.). On the other hand, if an abscess does not exist I am of the opinion that this small operation involves less risk to the patient than a slitting of the dura with subsequent explorative puncture, of the brain, whether that is performed with needle, knife or with Péan. In order to diminisk the risk of hemorrhage one can, following Reinking's suggestion, employ a needle that is not too sharp and which therefore can more easily glide past any vessel that might come in the way. And the danger of infection seems to me to be equally great with the slitting of the dura, since it leaves a wound which is afterwards constantly in contact with an infected area. In my judgment now the chance of a secondary infection from the frontal sinus to the contents of the cranium is rither increased than otherwise.

Therefore, when the dura is a little changed or not at all of abnormal aspect, I would choose puncture with a thick needle, without slitting, while as far as possible miking the puncture at a spot where the dura appears to be healthy.

If on the contrary considerable changes are found in the dura, especially tistula or great discoloration, an immecliate slitting of the dura should no doubt be considered, after the diseased area has been exposed to a sufficient extent. In such cases it may be assumed that the risk of an instrumental infection of the deeper-seated parts is especially great. If we in this case make a slit in the dura and keep the edges apart, we then get a view of the extent of the inflammation in the meninges and can better judge how and low far we must proceed inwards. In these cases the mode of procedure mentioned by Neuman $n$ (eit. from Reinking) will probably be often suitable. He makes a cross-shaped incision in the dura and waits till the cerebral matter presses out into the opening and then punctures the brain. If the cerebral matter does not press forward, that fact speaks strongly against the 
supposition that an abscess exists. In such a case onc must only adopt a waiting position.

How far in is it permissible to insert the puncturing instrument? Denker has in adults measured the distance between the foremost pole of the frontal lobe and the foremost horn of the lateral ventricle in a horizontal plane about 2.5 centimetres above the floor of the anterior. cerebral pit. The distance is from 2.7 to 3.9 centimetres: on an average 3.3 centimetres. He therefore asserts that one can go 2.5 centimetres in without risk. If we are moving in a plane that lies only from 1 to $2 \mathrm{~cm}$. above the floor of the cranium, we may go to a depth of 4 or 5 centimetres.

Now that the abscess has been found it must be evacuated. How? Most authorities seem to have adopted a comparatively long incision in the dura. Some of them lay special emphasis on this. Many employ a cross-shaped incision (Macewen, Gerber, Körner, Bönninghaus. Tohermann. Imhofer, Passow). Others regard a smaller incision as better (Dean, Büller, Denker), especially with regard to the danger of prolapsus. Miodowski (Brieger's clinic) asserts that one must go cautiously to work in order not to loosen existing adhesions.

The opening of the cerebral abscess itself can be performed with a knife, but a Pean's forcerps is especially in favour and we often see in the history of cases that it was only by the insertion of this instrument that the pus could be brought to run out, after incision with the knife had proved not to lead to the desired result.

Palpation of the abscess cavity with the finger is practised by some, but nobody seems to me to have given any satisfactory explanation as to what is attained by that exploration. Many also expressly warn us against this manipulation, which is, of course, not free from danger.

For the cleansing of the abscess cavity the methods employed are: wiping out, careful scraping with a shary) 
spoon and lavage. Thus Macewen washes out the cavityby means of 2 canulae, of which one is double as thick as the other, permitting the cleansing liquid (1\% carbolic solution) go in through the thin and come out through the thick canula.

Still, some authorst reject every form of wiping or washing out of the abscessu cavity (Alexander), and the same is true about rinsing Botey, Whiting and others).

In order to have a look in the abscess cavity various instruments hive been employed. Körner says that he has had much benefit from the use of Killian's long nasal speculum. Whiting has constructed an "encephalos"ope" of his own, which is shaped almost like a large anural speculum and provided with a conductor, which is removed after the instrument has been introduced. Whiting clivims that the encephaloscope has reduced the rate of mortality in his practice. A similar instrument has also been constructed by Uchermann aud it has been used in the Ear and Throat Department of the Rikshospital (no published record), but it has not been found servicable and was therefore abandoned. Finally I shall mention that Henke has for inspection of the abscess cavity emploved the bronchoscope, which is introduced without mandrin and thus can always be under the control oft he eye.

$\mathrm{By}$ means of these different instruments the authorities now think that they can control the abscess cavity, find out if the walls of the cavity have become glued together and separirte them, thus preventing retention of pus in recesses and the formation of secondary abscesses.

And now we arrive at the important subject of the ufter-treatment of the alscesses.

The operation has to perform the first task in the process of treatment, namely, the opening and evacuation of the abscess. Not less important is the second task. which lies with the after-treatment, namely, to provide a sufficient outlet for the secretion.

The main question in connection with the after-treat- 
ment, the pivot upon which the discussion revolves with practically speaking all the authorities, is this: Drainagetube or tamponade?

The choice between these two is difficult. This is shown not only by the fact that both methods have their adherents among eminent and experienced authorities, but is also proved by the circumstance that several operators have begun with the one method and afterwards gone over to the other. Nay, we actually meet with records in which we find the after-treatment in the same case legun in the one way and continued in the other.

Among the adherents of the drainage-tube method we find Macewen, Körner, Uchermann, Heine, Freudenthal. Henke, Rafin, Schmiegelow. Tanponade has been adopted by Denker. Passow. Eulenstein, Whiting, Herzfeld, Neumann, Müller (Trautmann's clinic), Miodowski (Brieger's clinic), Reinking, Alexander.

It may, however, here be added that Macewen, for example. only conditionally recommends the drainage-tube for acute abscesses. In case of foul abscess cavity he uses iodoform-gauze, changes every day and washes out the cavity. If, on the contrary, the abscess cavity is "aseptic", he employs an absorbable drainer (decalcitied (hicken-bone), the inner end of which just reaches inside the outer wall of the abscess and is sutured to the skin. This tube is left for 2 or 3 weeks. Heine inserts the drainage-tube nearly as far as the inner wall of the cavity. He emphasises that the drainage is imperfect, whether we use drainage-tube or tamponade. When the secretion has become insignificant be substitutes a strip of iodoform-gauze for the drainage-tube.

Röpke employs tamponade if the cavity appears clean, drainage when the secretion is more profuse. In this latter case he changes the dressings up to 2 or 3 times daily.

Among those whom bitter experience has converted frem the one methor to the other I shall mention the following: 
Bönninghaus employed at first the drainage-tube, but afterwards went over to the use of tamponade. He states. however, in his article on intracranial complications in connection with maladies of the accessory sinuses (1914) that the question is undecided. Büller (Scheibe's clinic) has had unfavorable experiences with tamponade and employs the drainage-tube when the secretion is more profuse. He points out, however, that the danger in the use of the latter is by no means slight.

Finally, I shall adduce one or two examples of cases in which the aftertreatment has wavered between both methods. In Paunz's case (rhinogenic frontal-lobe abscess) loose plugging was first adopted, 2 days later this was changed to the use of drainage-tube, 8 days after he again reverted to tamponade. Imhofer ( 2 otogenic temporal-lobe abscesses) employed in one case: drainage callargol-tampon - drainage fowing to retention behind the tampon) - tamponade (the drainage-tube was blocked by a coagulation). In the other case: drainage - gauzestrip dipped in paraffin liq. - drainage - gauze-strip with paraff. liq. He asserts that both the drainage-tube and the tampon have the defect that they fail to act on account of the secretion's "Eindickung". In order to counteract this he recommends (following v. Oettingen) a compress with physiological salt-water; still, the first dressings ought to be dry with a view of the possibility of hemorrhage.

It will therefore be seen that there seems to be good reason to assert with Bönninghaus that the question of drainage-tube or tamponade is still undecided.

It would be a tempting task to endeavour to throw light on this question by comparing the results attained by the different methods. Unfortunately, such a comparison would of a certainty bring us no nearer to the solution of the problem. In the first place, a perusal of the more complete statistical tables concerning cerebral abscesses (for instsace: Röpke's) shows us that the cases cured do not predominantly belong to any special method 
of after-treatment. In the next place, the results are also dependent on a number of other factors in the treatment, of which it is impossible to judge on the basis of the cases recorded. Finally, the abscesses, even in uncomplicated cases, have undoubtedly a prognosis which from the very beginning is different in the different cases, seeing that, amongst other things, it is dependent on the size, shape and situation of the abscess, on the nature of the infecting matter and on the constitution of the surrounding cerebral tissue.

There are still a number of questions regarding aftertreatment which I shall very briefly consider.

How frequently should the dressings be changed? Macewen here adopts a standpoint that is absolutely startling. In some cases, as mentioned above, he allows the first dressings to lie for 2 or 3 weeks. And he is able to record a case in which the dressings lay for 3 weeks and in which on their removal the wound was found to be completely healed. In the 25 years that have elapsed since that case was recorded no one has been able to report results that even approximately come up to the one mentioned. Most operators allow the first dressings to lie for 2 or 3 days and afterwards let the frequency of the changing be regulated by the amount of secretion or by any symptoms of retention that may appear. If there is much secretion some change the dressings as often as 2 or 3 times daily (Röpke, Imhofer). Also Senmann emphasises the importance of frequent changing. Speaking of a difficult case with profuse secretion, a large, tortuous abscess cavity and fetid pus, he says that the only expedient that availed in the end was to change the dressings twice every day. Finally, I may mention that Bönninghaus lays down the principle that the dressings should be changed every day, even if there is no pain, fever or other phenomena present.

The patient ought to be kept in bed for a long time after the operation. Macewen keeps the patient in bed $f_{\circ} 4$ or 6 weeks, even if he feels perfectly well and 
under no circumstances will he let him get up before the wound has been completely healed. He mentions a case of death, which he ascribes to cerebral oedema brought on by the patient's getting up too soon. Our 4th patient remained in bed for nearly 3 months, but after getting up there were slight increases in the evening temperature, whereupon he was again kept in bed for some weeks more. As no other reason for the rise in temperature could be proved to exist, we may reasonably assume that there still existed some changes in the surroundings of the abscess, which had not yet been completely eliminated and which annouced themselves on the alteration in the patient's mode of life. There is at any rate every possible reason for using the greatest cantion abont letting the patient get up.

Cerebral prolapsus has been once or twice mentioned above. This complication is of fairly frequent occurrence. It may cause difficulty in the after-treatment of the abscess and also represents in itself a certain danger. Attempts have therefore been made to prevent its occurrence. Thus some authors for this reason recommend that the incision in the dura should not be made too large iv. Bergmann, Bezold, Dean, Denker). Efforts have also been made to get the prolapsus to disappear after it has been formed by means of cautious compression and lumbar puncture, but it seems clear from the experience of the authors that the results have been rather doubtful. If the prolapsus interferes with the out-flow of the secretion it can be cut away (Heine), although this may give rise to unpleasant results, such as opening of the lateral ventricle and hemorrhage (Reinking). The simplest and least irritating treatment consists simply in the employment of ordinary sterilised dressings (Reinking). It must be remembered that when the increased intracranial pressure ceases with the cure of the abscess, or encephalitis, the prolapsus will then also as a rule disappear. An active treatment of the prolapsus will, therefore, generally speaking, be scarcely profitable. 
Before proceeding in conclusion to set forth the principles which in my opinion should be observed in the treatment of abscesses of the frontal lobe, I want to mention in a few words the data we are possessing regarding spontaneous cure of cerebral abscesses.

That a cerebral abscess may be cured by absorption is mentioned in the literature as a theoretical possibility, but no concrete example of such a cure has been anywhere recorded.

Otherwise is the situation with regard to the question of cure by spontaneous bursting and evacuation of the abscess. In this connection I shall first mention what Kiirner points out, namely, that it is often possible anatomically to establish the existence of a communication between an otogenic cerebral abscess and the tympanum or the mastoidal cavity. It may therefore be assumed that in many cases there is an imperceptible discharge from the abscess through the ear. Profuse secretion, spontaneous evacuation of the abscess by this channel has also been observed (Randall, Gribbon), but without resulting cure.

There have, however, also been observed cases of real spontaneous cure, which seem to stand criticism and which have also been acknowledged by the various authors.

Sutphen observed a patient who suffered from extensive caries in the temporal bone and who presented symptoms of cerebral abscess (headache, vertigo, nausea, hemiplegy on the opposite side). These symptoms disappeared after considerable quantities of pus had spontaneously discharged themselves through the passage of the ear. Four months afterwards the patient died of carotidal hemorrhage. On dissection there was found in communication with the carious cavity in the temporal bone a cerebellar abscess and in front of this in the upward direction a cicatrized mass, which could have been nothing else but a healed abscess. Pollak, in the case of a 13-year-old boy, on whom he had performed total resection of the middle ear and in whom he the day after diagnosed a cerebral abscess, found that this abscess burst out spontaneously through the dura. The abscess carity was 
washed out and drained. The patient recovered. Urbantschitsch has reported a similar case. He performed on a lady the operattion of total resection: during this the dura was laid bare, but showed no pathological changes. After the operation there was increasing headache. On changing dressings about 9 days after. the operation there burst out "close upon quarter of a litre" of fritid pus. This proved to have come from an opening in the dura, through which a probe could be inserted seceral centimetres into the brain. The patient was cured.

Brieger records (in a letter to $R o ̈ p k e$ ) a case where the lura was exposed, but the operation interrupted owing to the langerous condition of the patient. The next day the cerebral atscess had burst through the dura spontaneously. The abscess wavity could be conventiently plugged through the natural opening. A cure resulted.

The total number of natural cures recorded is small. They merely prove that we must admit the possibility of a spontaneous cure. They cannot, on the hand, veil over the fact that the prognosis for a cerebral abscess without surgjcal treatment may practically always be said to be absolutely bad. But from a pathologic-anatomic point of view they are of the greatest interest, and they show us how great are the healing powers that nature possesses. Those powers that in other parts of the body in numerous cases bring about a spontaneous cure of an abscess. I would here point to the every-day experience we meet with of a peritonsillar abscess bursting and healing up of its own accord. The same is the case with glandular abscesses in the various regions etc. I might also mention empyema e necessitate, and peritoneal abscesses of various origin which burst through to the intestine, to the uro-genital tract, in rare cases even through the abdominal coverings to the surface of the body.

Finally, - to come back to cerebral abscesses - I would point to nature's faculty of limiting the inflammation by the formation of adhesions in the meninges and in the membrane around the abscess. For therapeutic purposes attempts have also been made to encourage the formation of the meningeal adhesions. Thus Miodowski has proved by experiments on dogs that by introducing 
tampons with tincture of iodine between the bone and the dura adhesions may be produced in the subdural and arachnoidal spaces. $\mathrm{He}$ has also on a single occasion employed this method of procedure on a human subject, but there is no record of the result.

I have mentioned the few cases of spontaneous cure of cerebral abscess and the many evidences of what I should like to call nature's will to cure, because I think that they should be remembered and taken into account in the treatment of cerebral abscesses.

In conclusion I shall, on the basis of medical literature and of our four recorded cases, especially the 3 last, endeavour to sketch the lines on which in my judgment the treatment and after-treatment ought to be conducted. And while in the preceding pages I have spoken chiefly of berebral abscesses in general (to the exclusion of the traumatic abscesses, in which the conditions are different), in what follows I shall have specially in view the rhinogenic abscesses of the frontal lobe.

The question of explorative puncture after exposure of the dura I have treated at some length above and would refer the reader to what has been said there.

The evacuation of the abscess when there is a fistula in the dura would accomplish by cautiously enlarging the fistula and extending the opening with a Péan's forceps. Should the dura be sound, I would make an incision of moderate dimensions, 1 to 1.5 centimetres. This opening I would cause to gape apart by means of a Péan, inserted so far that the point just reaches the level of the outer wall of the abscess. Wen the pus streams out through the opening it ought not all to be allowed to run out in a continuous stream. The evacuation should take place in successive relays. In this way, in the first place, the change in the intracranial pressure proceeds less suddenly. In the next place, it seems to me in some degree probable that by this means we get the walls of the abscess to draw together more concentrically than with a sudden evacuation of the pus. If this is right, the risk of the 
formation of recesses and pockets is thereby lessened. which is of importance, because they can give rise to the formation of secondary abscesses, with disastrous result.

My reason for making the opening in the dura comparatively small is that I would try to keep the incision within the area in which there are to be found adhesions between the meninges themselves and between them and the surface of the brain. Hereby we may hope to limit the possibility of the inflammation spreading further in the rerebral meninges. I also regard a small incision as favourable with a view to the possibility of a prolapsus. We (annot. of course, quite eliminate such a possibility by making the opening small. When the contents of the 'linium increase in size in consequence of inflammatory changes they will force themselves out through any opening, rven if it is not large. But with a small incision in the dura we can under favorable circumstances ensure that the cerebral matter drives the membranes before it, that we in other words get a sort of meningoencephalocele instead of an encephalocelé. This was the case with our 4th patient. The protrusion in the area of the wound which arose during the after-treatment evidently consisted of rerebral matter covered with the meninges. It could be observed that there was no protrusion through the incision itself, which lay at the apex of the protruding portion. The protrusion sulsided of its own accord in the rourse of a couple of months. It may therefore be assumed that during that time the contents of the cranium were increased in volume owing to inflammatory changes. It must be counted as all advantage that the protruding contents of the cranium were cluring the period mentioned protected by the dura mater: as the danger of infection with this form of prolajsus may be supposed to be less than with the ordinary form.

For fear of injuring the wall of the abscess and thereby causing an extension of the inflammation I would not undertake any wiping or scraping out of the abscess 'avity, nor any palpation with the finger. Much less Acts oto-laryngologica. 
would I attempt to remove the membrane of the abscess. The latter ought to be regarded as a natural safeguard which should be left untouched. Neither would I venture upon any syringing of the cavity, although it seems that such a measure, if cautiously executed, may in many cases he undertaken without causing damage.

As a rule I would employ neither drainage-tube nor tamponade of the abscess cavity in the usual manner. In the opening in the dura $I$ would insert either a drainagetube or a strip of gauze (the rhoice between which I legard as of little importance) only so far that they reach the entrance to the abscess cavity itself. All that can be obtained without at the same time running the risk of injuring the cerebral tissue surrounding the abscess is scarcely more than the prevention of the edges of the opening from sticking together. The object of keeping the incision open ran, perhaps, be best attained by employing a rubber drainage-tube in the first place. Afterwards I believe it is equally serviceable to use a strip of gauze, hecause this material is soft and therefore cannot occasion any merhanical lesion. Besides, the drainage-tube slips out more easily, even if it has been sutured to the skin. Imhofer's suggestion of the nse of paraffin-gauze seems to me to $e$ worth a trial.

In order to secure the best possible chance for a free utflow of the pus the dressings ought to be changed with sufficient frequency. Even the first dressings ought not to lie longer than 24 hours; and I would not hesitate to change them 2 or 3 times in the day, if there is profuse secretion and if on changing it is seen that considerable quantities of pus stream out through the incision in the dura. This opening should every time be made gape apart by means of a Péan (forceps), which, however, ought not to be inserted too far in.

As regards the nature of the dressings, I would employ the dry form. Should the secretion show an inclination to dry up, so that the dressing sticks to the wound, it may perhaps be advisable to substitute compresses with 
physiological salt-water solution. We can, however, under these circumstances employ Hydrogenhyperoxyde for loosening the dressings. The tendency of the dressing to stick to the wound can also be counteracted by strewing a powder (boric acid, vioform) on the wound.

The question of a protracted confinement to bed has been dealt with above. The treatment of possible coughs ir obstruction and other ordinary measures need not be discussed in detail.

If uncler the extremely conservative treatment alsove described there should arise symptoms pointing to retention. or secondary abscess. we shall then be obliged to make an attempt to go deeper in for the purpose of finding and evacuating the new pus-focus. Under such cir"umstances I would try Henke's suggestion of the bronchoscope, as that instrument has the advantage over the others proposed that we ane always able to control with the eve the depth of its insertion.

Thus I arrive at the conclusion that, in general, abscesses of the frontal lobe ought to be treated in a very conservative manner, as suggested in the therapeutic scheme sketched out above. In this way I believe that the patient can be saved in those cases in which the abscess from the beginning has a comparatively good prognosis. It is precisely in such cases that one ought to proceed cautiously. It must be remembered that, when a cerebral abscess has been evacuated, the walls of the cavity fall together very quickly and that the surrounding substance is very soft. The pulpy mass which is met with directly inside the incision is undoubtedly very sensitive to the introduction of foreign bodies (instruments, drainage-tubes, tampon). In these comparatively benignant cases a too vigorous therapeutic treatment may spoil the prospects of a favorable issue. On the other hand, in those cases where the abscess tends to take a more malignant course we cannot in any case expect the result which is often attained in otber parts of the body through vigorous surgical treatment. The material of the brain is much too delicate for that. We 
must accept the fact that cerebral abscess is a dangerous malady, which, even after being opened, has a doubtful prognosis. Of the 87 recorded cases of frontallobe abscess issuing from the frontal sinus (Bönninghaus) only 15 were cured.

It may perhaps with justice be objected that I have in an altogether too one-sided manner upheld the importance of a conservative treatment for these abscesses. Possibly. too, the reader will feel that I have been carried away by my gratification at the favorable result in the case in which the conservative principle was on its trial, and that I therefore have been too ready to draw general conclusions from the result in a single case. Yet $I$ hope that it will, nevertheless, be admitted that the views advanced find some support, not only $i$ the experiences of others as reflected in medical literature but also i general medical reasoning. Although, undoubtedly, there is need for further experience in the matter. What I have tried, above all, to emphasise as being important in the treatment is a principle that must always be held sacred by os, namely, the principle: "nil norere."

\section{II.}

\section{Other Intracranial Complications in connection with Inflamma- tion in the Accessory Sinuses}

The following acrount of cases treated is only to be regarded as a small contribution to our knowledge regarling the other intracranial complications in connection with inflammation in the nasal accessory sinuses.

In his book on these forms of inflammation $\mathrm{Hajek}$ in 1903 asserts that cavernosus thrombosis is the classical form of intracranial complication for inflammation of the sphenoidal sinus, just as cerebral abscess is for inflammation of the frontal sinus and meningitis for inflammation in the ethmoidal labyrinth. This classification, however, does not coincide with the actual facts, as later experience has pro- 
ved. Hajek has therefore in the edition for 1909 omitted the passage mentioned. The more comprehensive collection of records of cases (cf. Bönninghaus) which has by degrees been compiled proves that we may expect any kind of intracranial complication whatsoever in connection with all forms of inflammation in the accessory sinuses. The different complications. moreover, frequently occur in combination with each other. It is therefore scarcely feasible 11) make these cases of illness tit into a definite classification. Most complicated are those cases in which there is "umbined inflammation of the accessory sinuses. It is not rasy to determine in each separate case which of the accessory sinuses forms the starting-point for the combined pathological changes. Thus in one of the cases recorded below (Erling B.) we find on the one side a number of atfections of the accessory sinus and on the other side serveral intracranial complications.

\section{Intracranial Complications issuing from the Sinus Maxillaris.}

In proportion to the great frequency with which sinusitis maxillaris occurs the intracranial complications in connection with this malady may be said to be extremely rare. $\mathrm{Hajeh}$. who demands very strong proof's before admitting a direct etiological connection between the sinusitis and the cerebral complication, regards only 2 of the cases recorded up to the year 1909 as being absolutely free from doubt. But even if with Bönninghaus (and Dreyfuss) we go a little farther than this, the number is still very small. Bönninghaus reckons that of the cases recorded up to the year 1914 nine belong to this group, namely, 7 cerebral abscesses (combined with pachymeningitis, leptomeningitis or thrombosis), 1 meningitis and 1 thrombosis in the plexus ven. carotic.

Regarding the mode of infection Bönninghaus states that it is a question of septic osteomylitis and periostitis in the upper jaw-bone, generally of dental origin (the socalled Weichelbaum's phlegmon), which rises upwards 
from the upper jaw and infects the os frontis, the os ethmoidale. the os aygomaticum and tinally the cavim cranii or the contents of the orbita and in most cases: results in cleath from meningitis after the formation of a cerebral abscess.

Also Paun\% maintains that empyema in the maxillary sinus of dental origin is more malignant than that originating from the nose. He has observed 4 cases of dental sinusitis with serious complications, one of which had a fatal issue (cerebral alscess and meningitis).

Likewise the 2 following cases seem to confirm the view that sinusitis arising from the teeth is relatively malignant.

\section{Fifth Case.}

Johanne B., 11 years old. Admitted Aug. 12th 1906. I)ied Aug. 20th 1906 .

The patient got toothache on August 5th. A dentist extracted 1st molar in the upper jaw on the left side. After coming from the dentist swelling appeared in the left cheek. She became fererish. Next day matter istued from the left nostril. On August 7 th she visitel a cloctor, who immediately had her put into the Eye Department of the Rikshospital, where the following facts were observed: Both eye-lids on the loft side are swollen, especially the upper one, which is red and covers the upper part of the lower lid. The left bulb is displaced outwards and also a little downuards. Some tenderness in the eye-lids. Conjunctiva greatly congested, but not chemotic. Cornea, camera ant. otc. show nothing abnormal. The mobility of the eye somewhat restricted in all directions. No neuritis or stasis of the papilla. Patient says she can see just as well as before. In the lower portion of the forehead, over the bridge of the nose and over the left eye, there is a very slight prominence, in which fluctuation is felt, but where the coverings are pale, not oedematous. In the left half of the nose the lateral wall is seen to be much swollen. Temperature 38.2 General condition quite good, no pain. Mind perfectly clear.

On August 8th there also appeared some swelling in the eyelids on the right side. Operation under chloroform-ether narcois.

Puncture of the left maxillary sinus from the lower nasal passage brought out fetid pus. Afterwards a perforation is made up 
through the alveole of the extracted tooth, followed by syringing. Finally incision along the medial portion of the orbital edge and evacuation of a large quantity of fetid pus, mixed with blood, from a subperiostal abscess in the orbital roof, which was almost entirely hared of periosteum, and the posterior part of which was uneven and rough. Xeroform-gauze tampon. Compress. Evening temperature $\mathbf{3 9 . 5}$ Rather restless, perhaps not quite clear in mind.

August 9th. Morning temperature: 37.4. (In syringing the maxillary sinus some of the liquid comes out through orbital wound. Wer thi left side of the face, especially in the temporal region, there is considerable emphysem" of the skin. Duning the following days the condition was more or less unchanged. Evening temperature over 39.0. Rather restless on the night of August 11 th, when she was transferred to the Ear anl Throat Departement.

Hore the syringing was continued. The temperature remained steady high: 38 to 39.8. Al" abscess formed in the rigtht cyc-lid, and was lancel on August 15th. General conculsive twitchings on the night of the 18 th August. Next morning somewhat delirious. Pulse: 160 . On August 19th lumbar puncture and eracuation of a turbid liquicl, from which diplococci developed in broth. Increasing unconsciousness. Died on August 20th. Post-mortem refused.

\section{Epicrisis.}

It can scarcely be doubted that the acute maxillary sinusitis on the left side arising from the teeth was here the starting-point for the subsequent fatal complications. The course of the malady proceeded with sinister rapidity, seeing that only 15 days elapsed from the time the tooth was extracted till death supervened.

The inflammation seems to have transferred itself from the maxillary sinus through the roof of the latter to the orbita, owing to there being an open communication between these 2 cavities (previously formed opening? destruction?) This is indicated vith certainty by the fact that some of the liquid used in syringing came out through the incision that had been made above the eye. By what channel and in what manner the inflammation further extended to the cavum cranii cannot be determined, as no post-mortem examination was made.

That meningitis was present appears with certainty from 
the clinical observations. These afford no foundation for the assumption of the presence of other intracranial complications. We should not. however, for that reasun axclude the possibility of such complications being revealerl lig a post-mortem examination.

\section{Sir.rll arlss.}

Erling $B . .14$ years old. Armitted September 17th 1913. Died Sept. 2!th 1913.

At Christmas 1912 got a gumboil in the upper part of the mouth on the right side, where 2 premolars were extracted. At the same period be also got a purulent discharge from the nose on the right side. There has since continued to be a little swelling on the face. About a month and a half ago be went to a doctor, who performed puncture and syringing of the right maxillary sinus, and this was afterwards repeated 5 or 6 timos. During the syringing there came out pus and blood. List night he: had a rinding pain in the right eyp, which this morning was a little swollen. The swelling has since increased rapidly, so that he now cannot open the eyc. No headache, shivering or other phenomena.

Condition on Sieptember 17 th 1913.

Pulse: 104. Temperature: 38.4 (armpit). Right cheek somewhat swollen, no tenderness. Considerable oedematous swelling of both eye-lids. especially the upper one the right side. The eye cannot be opened. No swelling or tenderness over the frontal sinus. The upper jawbone seems to be somewhat thicker on the right side than on the left. No fistula after the 2 extracted premolars.

Anterior rhinoscopy: On the right side the mucous nembrane is greatly swollen and succulent. The nasal cavity is somewhat contracted owing to a crista septi. There is a quantity of thick muco-pus, which is specially localised to the middle and lower nasal passages. On the left side the mucous membrane is likewise swollen. There is hypertrophy of the concha inf.

Posterior rhinoscopy: In the naso-pharynx muco-pus, especially on the right side. Moreover, secretion is found in the middle nasal passage.

September 18th. Has slept quite well. Feels comparatively well. Temp. 38.3. There is some chemosis conjunctivae. Double vision on looking very far to the side and also in an upward direction. On puncture of the right maxillary sinus from the 
lower nasal passage thick, yellow, fetid pus drips out through the trochar-tube immediately after withdrawal of the needle. Radical operution of the sinus inuxillaris dexter under chloroform narcosis.

The cavity contains large quantities of granulations. Iodoformganze tampoon, introduced through the nose.

Sept. 19th. Temperature resterday evening, .39, to-day 38. This forenoon shiverings and vomiting, with rise in temperature to 39.7. Since vesterday drowsy, but clear-minded. Complains of headache. Oedima ower eje has somewhat increased. Operution of the sinus frontutis dexter under ether nurcosis.

The coverings very oedematous. Upened frontal sinus from the anterior wall. The cavity contains pus and mucus, as well as granulations. Removed upper part of proc. frontalis max. sup. The anterior ethmoidal cells are full of granulations and are removerl. Iodoform-gauz" tampon, introduced down through the nose.

sept. 21st. Has felt somewhat better since the operation. Timp. yesterday $3 \pi_{.3}$ to 3i.5. To-day 37.1. Still much swel. ling of upper eye-licl.

Sept. 22nd. Temp. torlay 39.5. In the lateral part of the upper eye-lid there is a perforation, through which there comes a large quantity of fetid pus. In the inner part there is a necrotic area as large as a 10-öre piece, from the edges of which there "xudes feticl pus. Between these two areas evelid shows bluish discoloration. Severo rhemosis conjunctivae. A transversal incision is made in the upper eye-lid. The tampon in the nose is renoved. Compress with boric acid solution.

Sept i23rd. Temperature: $40.2-40.8$ Iast night patient had pain in the right side and dry cough. No shivering, no headache. ferfectly clear-mind. Examination of chest: On the right posterior surface in the downward direction there is a slightly muffled sound and iceakened respiration. Around the papilla mammae typical hard somel as of rubbing. Profuse secretion from alscess in eve-lid. Det. Em. camphorae.

Sept. 24th. Conclition more or less unchanged. A shivering-fit in the forenoon.

Sopt. 25th. Muffled sound on the right posterior surface more pronounced. Counter-incision outwards of the right eye-lid.

Sept. 26th. Proof-punctwe of right pleura: oparue cellow liquid ixuded.

Sept. 2ith. Had a hal night with constant coughing. The liulse has, as during the preceding days, been between 100 and 120. went up to 144 last night. Respiration, which during the preceding days was from 36 to 40 , was at the same time 44 . After camphor-injection somewhat better. On morning visit, pulso? 
108, regular, good, Respiration: 32. Icteric roloration of skin and ronjunctiva.

Sept. 29th. Puncture of the pleura with Potain's apparatus. Evactuation of about 100 cubic centimetres of liquid mixed with hlood. During the clay several fits of shivering, with temperature 40 and 40.5. At 7.30 p.m. a fit of coughing, luring which lw coughed up about a pus-basinful of bright. frothy blood. Died at 8 p.m.

Post-mortem exumination.

The right frontal sinus contained thick, mucous pus. The mucous membrane was thick and coated with granulations. The described changes around the right eve corresponded to a propagation of the inflammation along the upper orbital edge extending outwarls towards the temporal excavation on both the upper and under side of the arcus zygomaticus. The tissue here showed gremish liscoloration, infiltrated with pus, the periosteum partially removed. 'The corresponding spot on the inside of the cranium likewis. showed pronounced greenish discoloration; hore there was also found a scanty coating of pus. The bone of the rranium was not affected. It this spot there was also found discoloration and roating of pus on the outer side of the dur and minute hemorrlinges on its inner side, but no breaking through. Continuing from the spot mentioned there was found greenish discoloration of the orbital roof on the right side. The bone of the orbital roof was diffusely infiltrated with pus. The soft tissues in the orbita were infiltrated with thin, yellowish-green, fetid pus, as in de iffuse phlegmon. The inflammation was chiefly confined to the peripheral portions of the orbita. The bulbus was not attaked. lrom mentioned portion of the dura a yellowish discoloration stretched upwards towards the middle line, where an abscess the size of it grain of corn was found directly to the right of the sinus sayittalis sup. The sinus sagittalis, on being opened, was found to contain, from this spot and for about 10 centimetres in the backward direction, soft greyish-red, infected thrombi (thrombophlebitis). The other blood-sinuses were intact. The right maxillary sinus contained fetid pus as well as rags of greyish-green, nccrotic material. The mucous membrane was infiltrated with pus and partially dissolved, so that bare, infected bone was exposed to view. Similar infection with fetid, gangrenous contents in the rmoilal cells and in the sphenoidal sinus. Nowhere was there perforation to the base of the cranium.

The left maxillary sinus and the orbita were unaffected.

There was further found a fibrino-purulent pleuritis of the right side. In the right lung small yellowish-green abscesses directly under the pleurn. Tho lower part of the lung was almost in its 
nntity occupied by an irregularly formed infiltration of inflammatory nature. In this there was a gangrenous cavern almost the size of a hen's egg as well as a number of smaller ones. In these caverns there were quantities of fluid or coagulated bloorl, which also partly filled the larger and smaller bronchial tubes. Over the upper lobe of the left lung there was a newly-formed fibrinous coating. The spleen was swollen. Parenchynatons degeneration of the organs. General anemia.

\section{Elicrisis.}

Also in this case the starting-point for the different pathological changes was a sinusitis maxillaris arising out of dental periostitis. But in this case the sinusitis wis chronic, as it had existed for three quarters of a year before the symptoms appeared that introduced the final act with its rapid development. That the primary inflammation of the accessory sinus is to be sought for in the sinus maxillaris we may be permitted to deduce from the fact that the secretion fro mthe nose commenced at the same time as the symptoms of dental periostitis. Theoretically, it can, of course, not be denied that one or more of the other affections of the accessory sinuses which came to light through the operation or the post-mortem may previously have been present in a latent form. But such a supposition must be described as exceedingly improbable. and we shall scarcely be wrong in leaving this possibility out of consideration. Rather conld it he asserted that the periostitis in the upper jaw arising from the torth must be regarded as the actual original malady, which afterwards extended upwards, whilst the inflammation in the upper maxillary sinus was only a partial phenomenon. Some support for such an assumption can no doubt be found in the swelling of the upper jaw. which persisted the whole time after the extraction of the tooth. Nevertheless, I believe it is most correct to regard the sinusitis as the main malady, partly on account of the extensive anatomical changes in the antrum of Highmore that were brought to light by the post-mortem, and partly on ac- 
rount of the course we may assume the infection to have taken, compareing the clinical phenomena with the anatomical changes revealed by the post-mortem. This course seems to have been as follows:

From the maxillary sinus the infection has forced its way through the roof of that sinus to the orbita, where there arose a phlegmonous inflammation of the tissue around the bulb and a periostitis and osteitis in the orbital roof. The plegmonous inflammation further spread itself along the orbital edge out over the temporal excavation, where the inflammation attacked not only the periosteum but also the bone of the cranium itself the greenish discoloration was also distinctly evident on the inner side). From here the inflammation extended to the dura mater with pronounced signs of parchymeningitis. From the temporal region there stretched a distinctly pachymeningitic stripe right up to the middle line, where a small abscess had formed in the dura. For a distance of about 10 centimetres in the backward direction from this abscess there was a thrombo-phlebitis in the sinus longitudinalis with masses of softened thrombi. This thrombophlebitis must be regarded as the source of the pyæmic changes in the lungs and pleura. The immediate cause of death was then the violent hemorrhage in the lung, caused by the erosion of a large vessel in the gangrenous part of the lung. The patient's death must, therefore, be regarded as being due to septo-pyimmia originating from sinusitis maxillaris with intracranial complications as a connecting link.

The inflammations in the ethmoidal cells and in the frontal and sphenoidal sinuses do not. judging from the anatomical discoveries, appear to have formed the starting-point for the intracranial complications. It must be deemed probable that these affections of the accessory sinuses have been of a secondary nature in relation to. the inflammation of the maxillary sinus. 


\section{Intracranial Compllcations issuing from the Sinus Sphenoidalis.}

Of such complications there have, according to Bönninghaus, been recorded 52 cases, namely: 1 cerebral abscess, 27 cases of meningitis and 24 of thrombois in the sinus cavernosus (with or without meningitis). Frequently we find distinct macroscopic signs of decomposition in the walls of the sphenoidal sinus, as in the case recorded below. When the bony walls are macroscopically unchanged, the infection must be assumed to have been brought about by a thrombo-plebitis in the veins that form the connection between the veinous system in the mucous membranes of the accessory sinuses and the valscular apparatus of the meninges (Hajek).

\section{Seventh Case.}

Krarsten S., 8 vears old. Admitted Feb. 3rd 1914. Died Feb. th 1914.

Has had nasal catarrh for a long time. Un January 30th the right upper eyelid began to swell. This swelling increased rapidly, so that from the following morning he has not been able to open the eye. On Fehruary 1st there also appeared a swelling over the left rye and in the forehead. In the afternoon he began to wander and has since become more and more delirious. To-day he is completely unconscious. The swelling has further increased and has extended to the lower eye-lid.

Condition on Feb. 3rd. 1914.

The patient is unconscious, moaning and restless. Does not re-act when spoken to. Pulse: 180-190. Temperature: 39.4 . Heart and lungs: nothing abnormal can be noted.

Oedematous swelling in the forehead as well as in the upper and lower cye-lids on both sides. The eves are quite closed. The skin over the right eye shows bluish discoloration. The edges of the eye-lids are stuck together with a little pus. The right eye seems somewhat protruding. Chemosis conjunctivae with extravasation of blood. He winces on pressure along the eye-brow on both sides, especially in the medial part. On anterior rhinoscopy a little dried up pus is found in the middle nasal lassage on both sides. 
(opening of both fiontal sinuses under light cloroform narcosis.

To pus was found here, nor in the ethmoidal cells (the sphenoidal sinus was not opened).

Fel. 4th. The patient has been unconscions the whole time. No convulsions. Died at $4.30 \mathrm{p}$. $\mathrm{m}$.

Post-mortem examination.

It the base of the cranium to the left of the sella turcica rorrsponding to the apex of the left temporal lobe there was a scanty collection of yellow, thinly fluid pus. The outer walls of the selln turcica show's erosion and are coated with pus. In the sinus sphenoidalis there is found a large quantity of bloody, purulent exudation with decayed bone-substance. Forwards and upwards in the right orbital cavity there is a collection of yellew, thinly fluid pus. There is pus along the 1st branch of the: trigeminus on both sides in the direction of the orluita. No formation of thrombi in thr. reins coming from the orbita. No pus in the cellulae ethmoidales. No diffuse meningitis, only extreme hyperæmia of the whole surface of the brain. Only at the base around the chiasm is there found pus. No pathological changes in the ossa temporalia.

In the lungs are found numerous bluish-red alscesses, varying from the size of a pea to that of a hazel-nut. These are harl and infiltrated. On being cut through they prove to consist of a cuntre of separate pus-foci surrounded by a hemorrhagic zone.

Bacteriological test: From the cardiac blood and from the spleen there developed Gram positive diplococci, which on being inoculated into a mouse proved to be pneumococci.

Epicrisis.

The fact that the patient had suffered from nasal catar' for a long time may probably be taken as indicating the presence of sinusitis sphenoidalis of elder date. The acute exacerbation (new infection?) proved to be of a very malignant nature. Five days after the appearance of the symptoms the patient was dead. The progress of the malady was as rapid as in the case of pneumonia. The bacteriological examination of the blood and the spleen also showed that there was a general infection with pneumococci.

The changes found in the sphenoidal sinus and its osseous walls, as well as the negative discoveries in the other accessory sinuses, leave hardly any room for doubt that the meningitis (and the general infection) were due to the 
presence of inflammation in the sphenoidal sinus. (In the record of the post-mortem there is nothing noted regarding the sinus cavernosus.

The clinical diagnosis was not easy. The rhinoseopic changes were insignificant. The tenderness observed in the region of the forehead had a misleading effect, as it directed attention to the frontal sinus. The case in this respect reminds us somewhat of a case of isolated sinusitis sphenoidalis reported by Trautmann, in which there also was performed operation of the frontal sinus, exposure and puncture of the dura, as well as total resection of one middle-ear, as there was present an otitis of old date. The post-mortem revealed basal meningitis issuing from the sphenoidal sinus, cavernosus phlebitis and septico-pyamia. Trautmann also draws attention to the especial difficulty in the diagnosis in cases of acute sinusitis with very rapid development. We may. however, find a meagre consolation in the fact that no one has vet succeeded in saving a patient suffering from a suppurative intracranial complication arising from the sphenoidal sinus.

\section{Intracranial Complications of uncertain Origin in connection with combined Inflammations of the Accessory Sinuses.}

In some cases of intracranial complications in connection with inflammations of the accessery sinuses it is not. possible to determine from which sinus the contents of the cranium have been infected, because we have before us a polysinusitis or pansinusitis in which the pathological -hanges do not point to a certain accessory sinus as the starting-point of the trouble.

Gerber in his work on complications of the frontal sinus has tabulated from the literature 19 caces of this kind. All of these patients died except one, who suffered from rhinogenic pyæmia and with whom the author (Grunert) conjectured the presence of sinus-thrombosis.

The following case is an example of rhinogenic cerebral complication of uncertain origin. 


\section{bighth ('use.}

Agnes, $F ., 50$ yours old. Arlmitted February 17th 1918. Died Feb. 21 st 1918.

Previously always in good health. Since Sew Year has hal nasal catarrh and been troubled with mucus in throat. On February 7 th she became ill, had temperature about 39, and healache at base of skull, which, however, she had previously had to some degree. On Feb. 14th herpes was observed on the lower. lip. She has had slight fits of shirering, but not algor. No rough. Un Feb. 16th was examined in Lovisenherg Infirmary: Pulse 104. Respiration 32, Temperature 39,3. Tongue dry am coated. Slight oedema on crura. Stiffnes in back of neck. Kernig: slightly positive. Possibly somewhat shorter percussion-sound over posterior surface of right lung in the lower part. (1)therwise nothing noteworthy on examination of organs. Lumbur puncture, whereby about 10 cubic centimetres of turbid liquid were evacuated. On centrifugation a large amount of purulent sediment, consisting of polynuclear leucocytes. Pressure: 2+0 min. (after evacuation of a quantity of liquid) There were found no meningococci. nor any extracellular cocri.

Condition on Feb. 17th (Cillevaal Ejpidemic Department).

Condition as described above. Lumbar puncture with +racuation of about 40 cubic centimetres of turbicl liquid. Urine: all) anen positive.

Feb. 18th. A little sluggish, but clear of minl. Over pmsterior surface of right lung a slightly mufflerl sound heard on percussion, weakened sound of respiration and a few small rales. Stiffness in back of neck. Kernig: negative. Babinsky: negative. In the puncture from yesterday are found bacilli, of which some are mobile. They are coloured with Gram. In the culture the same bacilli are found. No Gram negative diplococci. Lumbal puncture with evacuation of 20 cubie centimetres of diffusely turbid liquid. Blood count: 34,400 white corpuscles. Widal: negative.

In the evening. Lumbar puncture with evacuation of 30 cubic centimetres of turbid liquid and injection of 20 cubic centrimetres of meningo-coccus serum.

Feb. 20th. Condition more or less unchanged. Lumbar puncture (25 cubic centimetres) and injection of 0.20 optochin. hydro(hlor. In the course of the day she got drowsy.

Feb. 20th. Since last night she has not been quite clear of mind. Skin and sclerae sligthly yellowish in rolour. Since 
yesterday bowels moved 8 times, excretion being very thin and passed in bed. In the evening absolutely no reaction. Lumbar. puncture with evacuation of thick greyish-yellow pus. In smear preparation were found Gram negative bacilli, partly intracellular and lying in heaps. Possibly also some Gram positive bacilli. No growth of typhus-bacilli from the fæces.

Died on Feb. 21 st at 3 a. $m$.

Post-mortem examination. (Only opening of the cranium was permitted).

Nothing note-worthy on the outer parts of the cranium. Some hyperæmia in the dura. In the soft meninges on the convexity of the brain nothing particular noted. On the other hand, at the bast there was found a thick fibrinopurulent coating on the under side of the anterior part of the right parietal lobe and upwards in the fissura Sylvii. In the backward direction there was also found a very thick solid fibrino-purulent coating on the under side of the pons and inwards along the clivus on the front of the medulla oblongata. A little turbid liquid in the ventricles of the brain. The brain itself showed slightly ftattened convolutions and shallow sulci, but otherwise usual conditions. On the right side the sinus sigmoideus was filled with softened purulent trombi. On resection of both middle ears these were found to be normal. The drums were smooth and specular. On both sides the ethmoidal cells as well as the frontal sinus and the spheonidal sinus were found to be filled with thick, tough mucous pus. (The maxillary vinus was not opened).

Bacteriological investigation; In the culture from the contents of the cerebral ventricles there developed a number of different microbes, both Gram-positive and Gram-negative bacilli and cocci.

Autoptical diagnosis: Meningitis cerebro-spinalis. Ethmoiditis, sinusitis frontalis et sphenoidalis suppurativa. Thrombosis sinus $\therefore$ igınoidei.

\section{Epicrisis.}

The symptoms of an affection of the accessory sinuse: were in this case not very pronounced. They were confined to nasal catarrh and phlegm in the throat and evidently little attention was paid to them by the patient. After there had been fever and indefinite symptoms lasting for about 1 week there appeared distinct signs of meningitis, the etiology of which was not clear. The presence of herpes in combination with the lack of a definitely determined starting-point led to the suspicion of 
epidemic cerebro-spinal meningitis. The bacteriological examination of the lumbar puncture showed, however, that such an axsumption was not tenable. The autopsy revealed no other etiological explanation of the meningitis than the existing inflammations in the nasal accessory sinuses.

On the basis of the description of the autopsy it is not possible to determine from which of the accessory sinuse: the meningitis proceeded (sinus spbenoidalis?). As no pithological changes were found in the temporal bones, it is reasonable to issume that the thrombosis found in the sinus sigmoideus was secondary in relation to the meningitis.

In eoncluding this little work I beg the J'rincipal of Ear and Throat Department of the Rikshospital, Professor $r$. Uchermann. to accept my best thanks for the material placed at my disposal. I likewise thank Dr Ustvedt. Chief Physician, and Ir Heiberg Hansteen. Demonstrator in pathologic Anatomy. for the permission to make use of the case recorded from Ulleval Hospital.

\section{Bibliography.}

Alexander, (i., Die Ohrenkrankheiten in Kindesalter. Leipzin 1912.

Bönninghaus, Die Operationen bei den intrakraniellen Komplikationen dẹr entzündlichen Erkrankungen der Nebenhöhlen. In Kat\%, Preysing a. Blumenfeld, Handb. der spec. chir. ete. 2 Aufl., 1914.

Hutzengeier, 0., Zur Chirurgie des Stirnhirnabscesses. Ein Fall von geheiltem Stirnhirnabscess. M. m. W. 1911 Ref. C. f. Lar., 1912.

Haller, Georg, Die Nachbehandlung des Hirnabscesses mit besonderer Berücksichtigung des Kleinhirnabscesses. A. f. 0. $98,1916$.

Cargill, Abscess des linken Stirnlappens ron einem Empyem der liuken Stirnhöhle ausgehend. C. f. Lar., 1909. 
Wean, I. W., Zur Technik der Operation des otitischen Hirnabscesses. Ann. of $10 t .$, Rh. and I sar. 1!10. Ref. (.. f. ()., 1911 .

Denker, Alfred, Rhinogener Frontallappenabscess und extrarluraler Alsscess in der Ntirngegend, durch Operation geheilt. A. f. L. ete. Bid. 10, 1900 .

Donalies, Fin rhinogener Hirnabscess. A. f. O. Bd. 7j, 1908.

Dreyfuss, R., Rhinogene (iehirnaffektionen. (.) f. U. Bd. 61908 .

Lulenstein, H., Mittheilungen uher den tiefen Hirnabseess bei acuten Erkrankungen im Schläfenbein, nebst Bericht ubor einen operativ geheilten Fall ron Grosshirnabsress. M. f. O., 189.5.

Freudenthal, W., Die intrakraniellen Komplikationen nasalen Ursprungs. A. f. I. etc. BH. 22, 1909.

fierber, I'. H.. Die Komplikationen iler Stirnhöhlenentzündungen. Berlin 1!)9.

Gerber, B. H., Rhinogener Hirnabscess. A. f. I. etc. Bd. 16 , 1904 .

firïnwald, L., Rhinogene Gehimaffeltionen. C. f. O. Bd. fi, 1908 .

Grünwald, L., Stinkende Naseneiterung. limpyen beider Stirnhölılen, cariosse Zerstiorung der Hinterwand derselben, rechtseitige P'achumeningitis, Abscess des Frontallappens. Trepanation. Heilung. II. II. IV. $1895,20$.

(iuttmann, Arthur, Die Gehimpunktion. C. f. O. Bd. 9, 1911. Hajek, M., Pathologie w. Therapir d. entzandlichen Erkr. d. Nebenhohlen al. Nast. 2 Aufl. 1903 and 3 Aufl., 1909.

Hajek, M., Ein Britring zum Sturlium des Infektionsweges bei der rhinogenen (iehimkomplikation. A. f. L. etc. Bd. 18, 1906.

Hammersfahr, Stirnhirnabscess. D. m. W. 1907. s. 659.

Heimann, Th., Empyrma antri Highmori et sinumm frontalium. Abscessus cerebri. VIrs. \%. f. O. Bd. 32, 1898, s. 41 .

Heine, B., Uperationen an Ohr. Berlin 1904.

Heine, 13., Die Prognose des utitischen Hirnabscesses. Passowsichäflus Beitrige ete. Bd. 2, 1909.

Henke, F., Zur Diagnose und Thrompie des Himalıscesses. A. f. U. Bd. $\$ 6,1911$.

Herzfold, Rhinogener Stimlappenabscess, durch Operation geheilt. B. kl. W, $1401,4 i$.

Hoffmann, R, Die orbitalen Komplikationen der Nebenhïhlen. In Katz, Preysing a. Blumenfeld, Handb. d. sper. Chir. etc. 2 Aufl., 1914.

Holmgren, Gunnar, Diblsfall a Sabbatsbergs sjukhus for oron, näs- och strupsjuka under i̊r 1916. Nordisk tidsku. f. Otorhino-laryngologi. Bd. 2, 1917. 
1 mhofer, R., Zur Kasuistik der otogenen Schläfenlappenabscesse hinsichtlich der Nachbehandlung. M. f. O. 1917.

Killian. Gustav, Die Krankheiten der Stirnhöle. In Heymann. Handb. d. Lar. u. Rh. Bd. 3, 1900.

Killian, Gustav, Die Killian'sche Radicaloperation chronischer Stirnhöhleneiterungen. A. f, L. etc. Bd. 13, 1903.

Killian, Gustav, Die Thrombophlebitis des oberen Längsblutleiters nach Entzundung der Stirnhöhlenschleimhaut. $Z$. f. $O$. Bd. 3T, 1900.

Knutson, Erik, Några fall av varbildning i näsans bihålor med intrakraniell komplikation. Nordisk Tidskr. f. Oto-rhinolaryngologi. Bd. I, 1916.

Korner, Otto. Die otitischen Erkrankungen les Hirns, der Himhilute und der Blutleiter. 3 Aufl., 1902.

Körner, Utto, Nachträge. 1908.

K ummel, Remarks on the 4th Versamml. 1. deutsch. otol. Ges. 1895 . A. f. (). Bd. 39,1895 , s. 134 .

Macewen, Pyogenic infective diseases of the brain and spinal cord. Filasgow 1893.

Meurers, Über 4 im Anschluss an eitrige Nebenhohlenerkrankungen entstandene Komplikationen mit totlichen Ausgang. Z. f. O. Bd. 60, 1910 .

Miorlowski, Felix, Beträge zur Pathogenese und pathologischen Histologic des Hirnabscesses (nebst experimentellen Untersuchungen über die Abdichtung des Arachnoidealraumes). A. f. O. Bd. 77, 1908 .

Müller, Richard, Zur Lehre ron den otitischen Hirnabscessen. A. f. (1) Bd. 50,1900 .

Maller, L., Ueber Empyem des Sinus frontalis und ethmoidalis. IV. kl. W. 1895.

Neumann, Heinrich, Zur Differentialdiagnose von Kleinhirnabscess und Labyrintheiterung. A. f. O. Bd, 67, 1906.

Onodi, A., l'ber die intrakraniellen und zerebralen Komplikationen der Nasennebenhöhlenerkrankungen. Z. f. L. etc. Bd. 3, 1910.

Oppenhoim, H., Die Encephalitis und rer Hirnabscess. Wien 1897. (In Nothnagel, Spec. Path. u. Ther.)

Passow, Zur Heilung der Hirnabscesse. Z. f. O. Bd. 37, 1900. Paunz, March, Ueber den rhinogenen Hirnabscess. A. f. L. etc. Bd. 13, 1903.

Paunz, March, Ueber die Komplikationen der dentalen Kieferhöhlenempyeme. C. f. L. 1911 , s. 594.

Pollak, Discussion in Oesterr. ot. Ges. M. f. O. 1897, sid. 563.

Prevsing, Hermann, Topographic und Operationstechnik der otitischen Schlüf enlappenabscesse. Z. f. O. Bd. 37, 1900 
Rafin, M., Des complications intracraniennes du sinus frontal. Arch. générales de médecine. 1897. Vol. II.

Reinking, Fr., Der Hirnprolaps in der Oto- und Rhinochirurgie. Z. f. O. Bd. 58, 1909 .

Reinking, Fr., Über die Gefahren der Hirnpunktion. \%. f. 0. Bd. 60, 1910.

Rische, Hans, Ein erfolgreich operierter Hirnabscess nach Stirnhöhle nerkrankung. Z. f. O. Bd. 62, 1911.

Ropke, Fr., Zur Operation des otitischen Grosshirnahscesses mit besonderer Berücksichtigung des Heilwerthes der Operation. Z. f. O. Bd. 34, 1899 .

Schmicgelow, E.. De otogene hjerneabscessers operationsteknik og deres efterbeh. Hosp.-tidende 1904, 30.

Schmiegelow, E., Contribution a la pathologie des absces du cerveau d'origine otique Aroh. int. de lar. etc. Tome XVII, 1905.

Sutphen, T. Y, Ruptur der Carotis interna in Folge von Nekrose des Schläfenbeins. Section. Z. f. O. Bd. 1T, 1887.

Trautmann, G., Akute Keilbeinhöhleneiterung mit intrakranieller. und orbitaler Komplikation. A. f. I. ete. Bd. 20, 1907.

Uchermann, V., Otitische Gehirnleiden. 1. Der otitische Hirnabscess. Z. f. O. Bd. 46, 1904.

Erbantschitsch, Fall von spontan durchgebrochenem Gehirnabscess. M. f. O. 1897 , s. 562.

Whiting, F., Die Drainage in der Hirnchirurgie. C. f. O. Bd. 8, 1910.

Whiting, F.. Demonstration des Encephaloskops. Z. f. O. Bd. $51,1906$.

Wiener, Alfred, Abscess in the frontal lobe of the brain after chronic frontal sinusitis. Ref. C. f. L. 1911.

\% a ufal, Discussion on the 4th Versamml. d. deutsch. ot. Ges. A. f. O. Bd. 39 , s. 135,1895 . 